\title{
A model-based comparison of extreme winds in the Arctic and around Greenland
}

\author{
Oliver Gutjahr ${ }^{1}$ @ । Günther Heinemann ${ }^{2}$
}

\author{
${ }^{1}$ Max Planck Institute for Meteorology, Hamburg, \\ Germany \\ ${ }^{2}$ Department of Environmental Meteorology, \\ University of Trier, Trier, Germany \\ Correspondence \\ Oliver Gutjahr, Max Planck Institute for \\ Meteorology, Hamburg, Germany. \\ Email: oliver.gutjahr@mpimet.mpg.de \\ Funding information \\ Bundesministerium für Bildung und Forschung, \\ Grant/Award Number: 03G0833D
}

This paper compares extreme value statistics of daily maximum $10 \mathrm{~m}$ wind speed in winter simulated by the regional climate model COSMO-CLM at a horizontal resolution of $15 \mathrm{~km}(\mathrm{C} 15)$ with the reanalyses ERA-Interim and Arctic System reanalysis (ASR version 1 and 2) and with a satellite data set (CCMPv2). Our C15 simulation (1979/1980-2015/2016, November-April) is thereby the longest highresolution simulation available for the Arctic. The results show that the extreme wind speeds tend to increase over the ocean with increasing the horizontal model resolution. A horizontal resolution of $\leq 15 \mathrm{~km}$ is required to sufficiently capture all extreme wind characteristics, in particular for the tip jets and barrier winds over the Irminger Sea and in the Denmark Strait, and for the low-level jets in the Nares Strait. Of almost equal importance are physical parameterizations of surface fluxes and of turbulence. Capturing extreme wind characteristics has a direct effect on climate relevant air-ice-ocean interactions, such as triggering open-ocean deep convection, polynya dynamics, or on the sea ice and freshwater balance of the Arctic.

\section{KEYWORDS}

Arctic, COSMO-CLM, extreme value analysis, POT, regional climate model, wind speed

\section{1 | INTRODUCTION}

The Arctic is one of the windiest areas worldwide (Sampe and Xie, 2007). Extreme winds in the Arctic and around Greenland are important for the local weather and for the global climate. They are crucial for exporting polar freshwater via the East Greenland Current (Spall and Price, 1998; Haine et al., 2009), for forcing the Irminger and Labrador gyre (Spall and Pickart, 2003), and for air-sea interactions that trigger open-ocean convection in the Nordic Seas (Pickart et al., 2003; Martin and Moore, 2007; DuVivier and Cassano, 2015; DuVivier et al., 2016). For instance, extreme winds enhance the heat loss from the Irminger Sea and cause deeper mixed layers on very short timescales (order of days) (de Jong and de Steur, 2016; DuVivier et al., 2016). Extreme cyclones interact with the sea ice year round (Simmonds and Keay, 2009), and in summer 2012 an anomalous cyclone strongly impacted the record setting September sea ice minimum (Simmonds and Rudeva, 2012). Of importance is in addition whether wind speed extremes show a trend over the last decades, which might affect the sea ice drift and thus the freshwater export (Spreen et al., 2011; Kwok et al., 2013).

Extreme winds are in particular generated in the vicinity of southeast Greenland, which is located at the end of the North Atlantic storm track. Here, mesoscale wind systems interact with the steep orography of Greenland and generate high wind speeds. Well known are westerly and easterly tip jets (Doyle and Shapiro, 1999; Moore, 2003; Moore and Renfrew, 2005; Moore et al., 2008; Våge, 2009; Moore and Pickart, 2012; Moore, 2014), barrier winds (Moore and Renfrew, 2005; Outten et al., 2009; Harden and Renfrew, 2012), katabatic winds (Heinemann and Klein, 2002; Heinemann, 2003; Moore et al., 2015) or low-level jets, for example, in the Nares Strait.

Extreme winds further constitute a hazard to marine activities (Hughes and Cassano, 2015), which are likely to 
increase in the future as sea ice is retreating (Stroeve et al., 2012) and large reservoirs of oil and gas will become accessible in the Norwegian and the Barents Sea (Gautier et al., 2009). Even coastal areas are endangered by storm surges (Brunner et al., 2004), which enhance coastal erosion (Harper, 1978).

For these reasons it is important to simulate extreme wind speeds adequately with climate models. Despite their importance, the intensity and frequency of near-surface winds are underestimated in state-of-the-art climate models because of the rather coarse horizontal resolution (Kolstad, 2008; Sproson et al., 2008; DuVivier and Cassano, 2016; Moore et al., 2016). The "effective resolution" is even lower and about 5-7 times the native grid resolution (Skamarock, 2004; Zentek et al., 2016). A sufficiently high horizontal resolution of atmospheric models is therefore crucial to simulate these mesoscale wind phenomena. As a circumvent, physical parameterizations for strong mesoscale winds were developed for stand-alone ocean models when forced with low-resolution atmospheric wind fields (Våge et al., 2008; Sproson et al., 2010; Condron and Renfrew, 2013; DuVivier et al., 2016). If the mesoscale variability is retained in the atmospheric forcing, the strength of the wind-driven gyre in the North Atlantic and the Atlantic meridional overturning circulation (AMOC) increased by $5-10 \%$ in a global ocean model (Jung et al., 2014). However, linking the strong, short-lived wind events and the slow, long-term AMOC is not easy to accomplish (Buckley and Marshall, 2016).

Regional climate models, however, are able to produce stronger wind speeds. When the horizontal resolution of the polar-adjusted Weather Research and Forecasting (Polar WRF) model was increased to $10 \mathrm{~km}$, the intensity of easterly tip jets increased by $5 \%$ to $11 \%$ (24-32\%) compared to a $25 \mathrm{~km}(100 \mathrm{~km})$ simulation (DuVivier and Cassano, 2013). Very high model resolution is for instance required for open-ocean convection in the Irminger and Labrador Seas; a process acting at horizontal scales of 1-10 km (Spall and Pickart, 2003; Martin and Moore, 2007). By comparing the global reanalyses ERA-Interim (ERA-I; Dee et al., 2011) with the regional Arctic System Reanalysis (ASR), Moore et al. (2016) found that ERA-I underestimates topographic induced high wind speeds in southeast Greenland. Compared to observational stations, a horizontal resolution of $15 \mathrm{~km}$ considerably reduced the wind speed biases. Based on a 2-year (May 2005 to June 2007) simulation with Polar WRF at $10 \mathrm{~km}$ resolution, Hughes and Cassano (2015) found that extreme winds ( $>99 \%$ percentile) enhanced in comparison with a $50 \mathrm{~km}$ simulation and with ERA-I. So far, however, no extreme value analysis (EVA) was conducted, based on a multi-decadal, high-resolution simulation. Further, almost all previous studies at high resolutions were based on Polar WRF, so that it is of interest how other RCMs behave. Finally, a new aspect of our study is the comparison of extreme wind speeds in the Nares Strait, where a resolution of $<30 \mathrm{~km}$ is required to resolve the air-sea interactions (Moore and Våge, 2018).

Motivated by the above mentioned short experiment by Hughes and Cassano (2015) and the improvements found by DuVivier and Cassano (2013), Moore et al. (2016), and Moore and Våge (2018), we argue that high-resolution climate models are able to better capture extreme wind events. Because of the very short simulation length in previous studies, we performed a 37 winter (November-April; 1979/ 1980-2015/2016) long high-resolution simulation with the polar-adjusted regional climate model (RCM) COSMOCLM (CCLM) at a horizontal resolution of ca. $15 \mathrm{~km}$ $\left(0.125^{\circ}\right)$. This simulation is referred to as $\mathrm{C} 15$ in the following. It is the first multi-decadal simulation at such highresolution for the Arctic. With our C15 simulation it is now possible to calculate extreme statistics based on sufficiently long time series. Because the most intense wind systems mainly occur in the Euro-Atlantic sector of the Arctic, we set a focus to that area. With this study, we aim to answer the following questions:

1. Are there substantial differences in extreme wind statistics between state-of-the-art models?

2. How does the horizontal resolution affect the extreme winds?

3. Are there differences at the highest resolution $(15 \mathrm{~km})$ ?

We calculated extreme indices and fitted general Pareto distributions (GPD) (Holmes and Moriarty, 1999; Coles, 2001; Gutjahr et al., 2016b) to the tails of daily maximum wind speed distributions. Then we calculated return levels (RLs) associated with return periods up to 20 years. RLs are of particular interest for risk assessment and for calculating the likelihood of climate extremes. Such an EVA provides more information of the distribution tails than a simple comparison of specific percentiles. Based on the fitted GPDs it is even possible to estimate extremes longer than the simulation period, which might be of importance given the high computational costs for high-resolution RCMs.

The paper is organized as follows: in section 2 we give an overview of the mesoscale wind systems that generate extreme winds in the Arctic and around Greenland. In section 3 we describe the configuration of the CCLM simulation, the reanalyses, and the satellite data set. Section 4 describes how we define extreme winds. The results are presented in section 5 and discussed in section 6. Finally, we draw conclusions in section 7 .

\section{2 | EXTREME WINDS GENERATED BY MESOSCALE WIND SYSTEMS}

Mesoscale tip jets are either westerly or easterly (so called reverse tip jets) and result from Bernoulli acceleration down the lee slope (Doyle and Shapiro, 1999) and acceleration 
around Cape Farewell (Outten et al., 2009)—the southernmost tip of Greenland (Moore and Renfrew, 2005). Easterly tip jets result from the adjustment of the barrier flow when the influence of the topography is not longer present (Moore and Pickart, 2012). In particular, westerly tip jets at Cape Farewell (Doyle and Shapiro, 1999; Moore and Renfrew, 2005; Våge, 2009; Moore and Pickart, 2012), but also barrier winds in the Denmark Strait, are most intense and often exceed $25 \mathrm{~m} / \mathrm{s}$ (DuVivier and Cassano, 2013). The frequent presence of these extreme winds cause the Irminger Sea to be the area with globally the highest frequency where wind speeds exceed 20 m/s (Sampe and Xie, 2007; Papritz, 2017).

Katabatic winds form all along Greenland's coasts (Heinemann and Klein, 2002; Heinemann, 2003; Moore et al., 2015) and plateau jets form over its ice sheet (Moore et al., 2013). A well known area of extreme and destructive katabatic winds that reach hurricane intensity, so called piteraqs (Klein and Heinemann, 2002), is the Ammassalik Island (southeast Greenland) and the surrounding Sermilik, Køge Bugt, and Ammassalik Fjords (Rasmussen, 1989; Heinemann and Klein, 2002; Klein and Heinemann, 2002; Oltmanns et al., 2014; Moore et al., 2016).

The katabatic winds push sea ice offshore the Ammassalik Island so that coastal polynyas form (Heinemann, 2003). In this way, but also when blowing over open ocean, katabatic winds enhance the oceanic heat loss and account for up to $20 \%$ of the wintertime heat loss in the Irminger Sea (Oltmanns et al., 2014), where in addition marine cold-air outbreaks frequently occur (Kolstad et al., 2009; Kolstad, 2015; Papritz and Spengler, 2016; Papritz, 2017). The marine cold-air outbreaks themselves constitute favourable conditions to form polar lows (Businger, 1985; Heinemann and Claud, 1997; Spengler et al., 2017), which generate extreme wind speeds over the Greenland, the Norwegian and, particularly, the Barents Sea. In marine, extra-tropical Shapiro-Keyser cyclones (Shapiro and Keyser, 1990) so-called sting jets may form at the end of the bent-back front (Browning, 2004; Schultz and Sienkiewicz, 2013; Schultz and Browning, 2017; Clark and Gray, 2018).

Although most intense around Greenland, extreme wind speeds occur, however throughout the Arctic. Known are tip jets at the South Cape of Svalbard (Reeve and Kolstad, 2011), at northeast (Tuononen et al., 2015) and northwest Greenland (Moore, 2016), at the tips of Baffin Island (Hanesiak et al., 2013), and in the northern Bering Sea (Cavalieri and Martin, 1994; Moore and Pickart, 2012), leaving the Siberian coast the windiest spot in the North Pacific Ocean during winter. At the Novaya Zemlya Archipelago, southeasterly wind speeds in winter generate the local Novaya Zemlya bora (Moore, 2013). The bora frequently forms wind-driven polynyas at the northwestern coast of Novaya Zemlya (Moore, 2013). The polynyas produce dense water and thus modify the entering Atlantic water in the
Barents Sea. Extreme wind speeds are further produced by strong pressure gradients between the Beaufort high and the Aleutian low over the Chukchi and Beaufort Seas (Stegall and Zhang, 2012).

A unique mesoscale feature are the low-level jets (LLJ) in the roughly $500 \mathrm{~km}$ long and $40 \mathrm{~km}$ wide Nares Strait (Samelson and Barbour, 2008) that connects the Arctic Ocean with the Baffin Bay via the Kennedy Channel and the Smith Sound (Figure 1b). These LLJ are caused by alongstrait pressure gradients combined with channelling effects due to the steep and narrow surrounding orography (Samelson and Barbour, 2008). The strong winds in the Nares Strait are important for the ice and freshwater balance of the Arctic Ocean (Samelson and Barbour, 2008). They are strongest at the southern exit of the Kennedy Channel and of Smith Sound, where the wind speeds can exceed $25 \mathrm{~m} / \mathrm{s}$ (Samelson and Barbour, 2008; Moore and Våge, 2018). Here, the North Water Polynya (Preußer et al., 2015) forms regularly, because of divergent sea ice motion that is caused by the strong wind stress. The North Water Polynya is of particular interest because it is one of the largest and most productive sea ice formation areas in the Arctic (Preußer et al., 2015). It is further a focal point for marine life (Stirling, 1997; Arrigo, 2007) and a site of oceanic convection and of atmospheric $\mathrm{CO}_{2}$ sequestration, slowing down global warming (Barber et al., 2001). To resolve the air-sea interactions over the North Water Polynya, a horizontal resolution of $<30 \mathrm{~km}$ was recommended by Moore and Våge (2018), based on a short model comparison for January to April 2016.

\section{3 | MODEL AND DATA SETS}

An overview of all data sets that are used in this analysis and are described below is given in Table 1 .

\section{1 | COSMO-CLM}

We performed a simulation with the polar-adjusted COSMO-CLM (CCLM) in version v5.0_clm1 (Gutjahr et al., 2016a) at a horizontal resolution of $15 \mathrm{~km}$ for the winter half-years (November-April) 1979/1980-2015/2016. The model domain (Figure 1a) covers the entire Arctic with $450 \times 350$ horizontal grid boxes and 60 vertical levels (24 levels below $2 \mathrm{~km}$ height) at a staggered Arakawa-C grid. The simulation was forced with ERA-Interim (ERA-I; Dee et al., 2011) without spectral nudging. We refer to this simulation as $\mathrm{C} 15$ hereafter. Figure 1b shows a close-up of Greenland and its surrounding seas, with sites of interest (see section 4).

The configuration of CCLM was based on Gutjahr et al. (2016a), which includes a modified version of the two-layer thermodynamic sea-ice module of Schröder et al. (2011) that has been implemented into CCLM by Gutjahr et al. (2016a). 
(a)

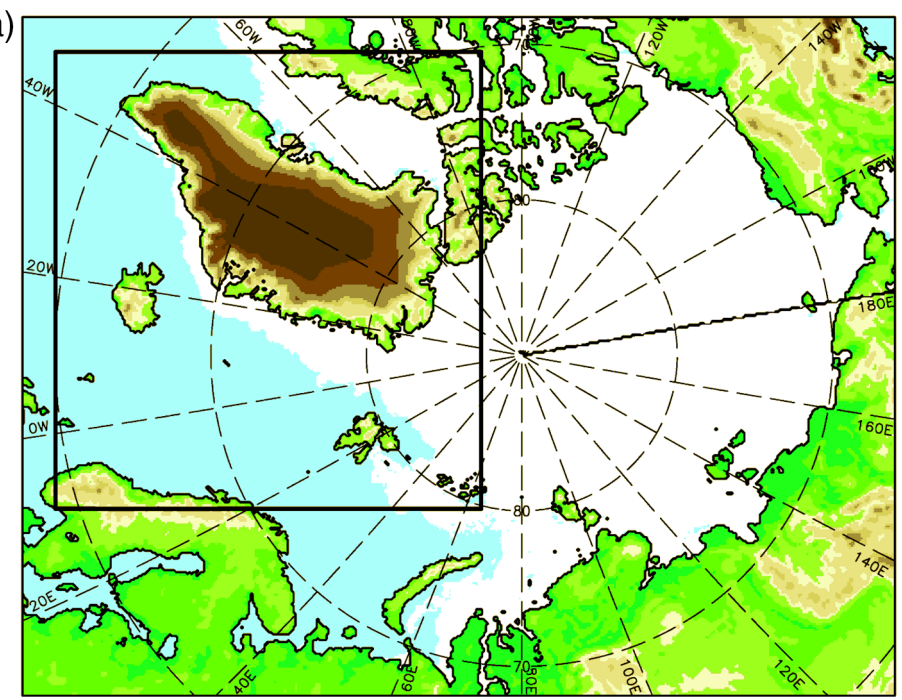

(b)

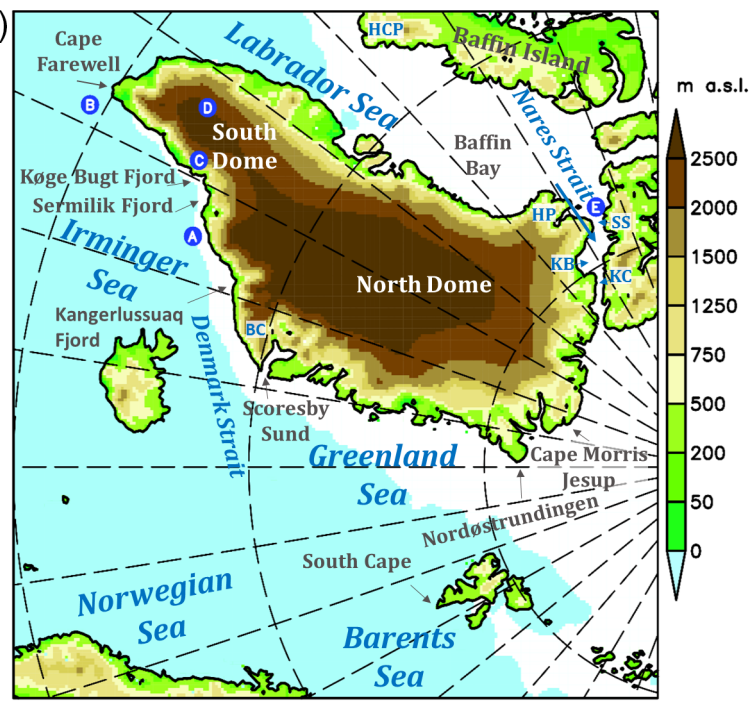

FIGURE 1 COSMO-CLM domain covering (a) the entire Arctic with a horizontal resolution of $15 \mathrm{~km}(\mathrm{C} 15)$ and (b) a close-up of Greenland and its surrounding seas (marked as a black box in (a)). The orography is colour-shaded and the sea-ice extent of a random day (January 5, 2008) is shown in white. $\mathrm{BC}=$ Blosseville Coast HP = Hayes Peninsula; $\mathrm{HCP}=$ Haines and Cumberland Peninsula; $\mathrm{KB}=$ Kane Basin; KC = Kennedy Channel; SS = Smith Sound. The dark blue symbols show the location of the sites: A: Irminger Sea, B: Cape Farewell, C: Køge Bugt Fjord, D: Greenland Plateau jet, E: Nares Strait. All sites were used for the return level curves in Figure 6 [Colour figure can be viewed at wileyonlinelibrary.com]

TABLE 1 Overview of the used model and remote sensing data sets of daily maximum $10 \mathrm{~m}$ wind speed $\left(U_{10 x}\right)$. The overlapping time period of all data sets is the winter half-years 2000/2001-2011/2012 (November-April). The last column shows how $U_{10 x}$ was extracted from the data sets

\begin{tabular}{|c|c|c|c|c|c|c|}
\hline Data set & Acronym & Institute & $\Delta x$ & Available period & Vertical levels & $U_{10 x}$ aggregation \\
\hline Cross-cal. multi-platform winds & CCMPv2 & NASA/GSFC/NOAA & $25 \mathrm{~km}$ & 1987-2016 & & $6 \mathrm{hr}$ to daily max. \\
\hline ERA-Interim & ERA-I & ECMWF & $80 \mathrm{~km}$ & 1979-2016 & 60 & $6 \mathrm{hr}$ to daily max. \\
\hline Arctic System Reanalysis & ASRv2 & & $15 \mathrm{~km}$ & 2000-2012 & 71 & $3 \mathrm{hr}$ to daily max. \\
\hline COSMO-CLM 15 km & $\mathrm{C} 15$ & MPI-M/Univ. Trier & $15 \mathrm{~km}$ & 1979-2016 (Nov-Apr) & 60 & $1 \mathrm{hr}$ to daily max. \\
\hline
\end{tabular}

It distinguishes a sea-ice layer and a constant snow-layer. Surface fluxes are calculated by a bulk transfer scheme with a stability dependency (Louis, 1979). Energy fluxes over fractional sea ice are considered by a tile-approach (Gutjahr et al., 2016a) for grid-scale and subgrid-scale sea ice. The vertical diffusion above the surface layer is parameterized by a level 2.5 closure scheme (Mellor and Yamada, 1974) based on a prognostic equation for turbulent kinetic energy. CCLM is coupled to the land surface model TERRA-ML (Heise et al., 2006) and includes terrestrial snow and ice surface treatments as well as surface flux calculations over land. The height of surface elevation of the Global Land One-km Base Elevation (GLOBE) Project (Hastings et al., 1999) is used for orographic height in $\mathrm{C} 15$ with eight soil levels (lowest at $14.58 \mathrm{~m}$ depth) and an additional prognostic snow layer above.

The sea-ice extent and concentration is prescribed daily (see Gutjahr et al., 2016a for more details). The Ocean and Sea Ice Satellite Application Facility (OSI SAF, version 1.2) product from EUMETSAT (EUMETSAT Ocean and Sea Ice Satellite Application, 2015) was used for prescribing the ice concentration. Thereby the OSI-409-a (v1.2) product covers the period before April 16, 2015 (SMMR, SSM/I, and
SSMIS data; Wentz et al., 2012) at $12.5 \mathrm{~km}$ horizontal resolution and the OSI-430 (v1.2) continues thereafter (SSMIS data; Wentz et al., 2014). Missing days were interpolated linearly in time.

The sea-ice thickness is prescribed daily from interpolated Pan-Arctic Ice Ocean Modeling and Assimilation System (PIOMAS) fields (Zhang and Rothrock, 2003). In polynyas, defined as areas with a sea-ice concentration $\leq 70 \%$, we assume $30-\mathrm{cm}$ thick grid-scale ice and $1-\mathrm{cm}$ thin subgrid-scale ice for the tile-approach. Outside polynyas (sea-ice concentrations $>70 \%$ ) the grid-scale ice thickness is that of PIOMAS and the subgrid-scale thickness was set to $1 \mathrm{~cm}$. See Gutjahr et al. (2016a) for details. Note that we used linear interpolated monthly fields of ice thickness until April 30, 2000 and daily fields from November 1, 2000 onwards. The sea ice surface temperature is initialized from ERA-I.

The model assumes a constant snow layer of $10 \mathrm{~cm}$ if the ice is thicker than $20 \mathrm{~cm}$. The sea-ice albedo is calculated every time step based on the Køltzow scheme (Køltzow, 2007), which includes a melt pond parameterization. The scheme calculates the sea-ice albedo as a function of the ice surface temperature and the ice thickness. 
C15 was run in a daily forecasting procedure starting at 18 UTC with a lead-time of $30 \mathrm{hr}$. The first $6 \mathrm{hr}$ were cutoff as spin-up time so that the simulation period covers a whole day. The output frequency was hourly for the nearsurface fields. The lateral boundaries were updated every $6 \mathrm{hr}$. This strategy of running CCLM (or the numerical weather prediction version COSMO) was successfully applied in previous simulation studies for the Arctic (Ebner et al., 2011; Schröder et al., 2011; Bauer et al., 2013; Gutjahr et al., 2016a). Gutjahr et al. (2016a) compared CCLM results to automatic weather stations over sea ice and found that CCLM is able to reproduce the observed nearsurface variables. Kohnemann et al. (2017) confirm these results using CCLM for the winter half-years 2002-2016. However, our simulation is the first multi-decadal simulation with CCLM for the Arctic.

\section{2 | Reanalyses and observations}

We compared the $\mathrm{C} 15$ simulation with the following reanalysis data sets (Table 1): ERA-I (horizontal resolution of about 80 km, 60 vertical levels); Arctic System Reanalysis version 1 (ASRv1; Bromwich et al., 2012) with a horizontal resolution of $30 \mathrm{~km}$; and ASR version 2 (ASRv2; Polar Meterology Group/Byrd Polar Research Center/The Ohio State University, 2017; Bromwich et al., 2017) at $15 \mathrm{~km}$. Both ASR models have 71 vertical levels. ASR is based on the Polar Weather Research and Forecasting (Polar WRF) model (Hines et al., 2015) that was spectrally nudged towards the ERA-I state. The 3-hourly ASR data sets are available for the period 2000-2012. The 6-hourly ERA-I and 3-hourly ASR data were bilinearly interpolated onto the C15 gird.

As reference we used the cross-calibrated multi-platform ocean wind vector analysis version 2.0 (CCMPv2) data set (Atlas et al., 2011; Wentz et al., 2015). The CCMPv2 data set is referenced to a height of $10 \mathrm{~m}$ by considering neutral stability. It is available up to $78^{\circ} \mathrm{N}$ for the period $1987-2016$ at a horizontal resolution of about $25 \mathrm{~km}\left(0.25^{\circ}\right)$ and a temporal resolution of $6 \mathrm{hr}$. CCMPv2 was bilinearly interpolated onto the $\mathrm{C} 15$ grid and the daily maximum wind speed was calculated from the 6-hourly values.

CCMPv2 uses ERA-I as a background field with assimilated measurements of ocean wind data from moored buoys and satellite data, including active sensors (e.g., QuikSCAT and ASCAT) and passive sensors (WindSat, SSM/I, AMSRE, AMSR2, and others). CCMPv2 falls back to ERA-I over land and over sea ice with possible deviations due to the interpolation onto the $\mathrm{C} 15$ grid (e.g., along coasts). A known issue is the underestimation of wind speeds $>25 \mathrm{~ms}^{-1}$ compared to individual satellite observations, which is caused by the too low wind speeds in ERA-I (Ricciardulli and NCAR Staff, 2016). A better agreement was found for wind speeds between 10 and $22 \mathrm{~m} / \mathrm{s}$ (Moore et al., 2008). Nevertheless, CCMPv2 is the longest, continuous observational satellite product with high spatial and temporal coverage and thus suited for extreme value analysis.

\section{4 | EXTREME VALUE ANALYSIS}

We based the EVA analysis on three time periods: (a) full period $1979 / 1980$ to $2015 / 2016$ (37 winter) for ERA-I and C15; (b) the overlapping winter half-years 1987/1988-2015/ 2016 (29 winter) of ERA-I, CCMPv2, and C15; and (c) the shorter period 2000/2001-2011/2012 (12 winter) where all data sets overlap with ASR. The EVA was based on the daily maximum $10 \mathrm{~m}$ wind speed $U_{10 \mathrm{x}}$, which was aggregated from the original output fields (see Table 1). Performing the analysis based on 6-hourly sampled output did not affect the results (not shown).

For every time period, we calculated extreme indices and return levels (RLs). A return level (RL) is the value that is statistically expected to be exceeded once in a given period of time (so called return period). We focus on the 10-year return levels $\left(\mathrm{RL}_{10}\right)$, but calculated RLs up to the 20-year return period. For a qualitative demonstration of associated uncertainties in different wind regimes, we selected five sites of interest (Figure 1b) for a more detailed analysis.

\section{1 | Extreme indices}

The first index is the $95 \%$ percentile $(95 p)$ of daily maximum $10 \mathrm{~m}$ wind speed $\left(U_{10 \mathrm{x}}\right)$. The $95 p$ values are later used as threshold parameters for the "peaks-over-threshold" (POT) method (section 4.2). In addition, we analysed the following indices as defined by the CCI/CLIVAR/JCOMM Expert Team on Climate Change Detection and Indices (ETCCDI): the number of strong gale days $\left(S_{g}\right)$, defined as $U_{10 \mathrm{x}} \geq 20.5 \mathrm{~m} / \mathrm{s}$; and the number of hurricane days $\left(S_{h}\right)$, defined as $U_{10 \mathrm{x}} \geq 32.5 \mathrm{~m} / \mathrm{s}$. These indices were applied to all individual grid boxes for every winter season and averaged over time afterwards.

\section{2 | POT method}

There are two types of extreme value distributions: (a) the generalized extreme value (GEV) distribution and (b) the generalized Pareto distribution (GPD) (Holmes and Moriarty, 1999; Coles, 2001). While the GEV is the limiting distribution for block maxima values (e.g., annual maxima), the GPD (Equation A1) is the limiting distribution for values exceeding a high threshold. The calculation of RLs based on fitting a GPD is referred to as the POT method (Coles, 2001; Ghil et al., 2011). The benefit of the POT method is the usage of more information from the data compared to the block-maxima approach. The difficulty is, however, to determine an optimal threshold that is high enough to ensure realizations of the GPD but low enough to ensure a sufficiently large sample size (trade-off between bias and variance; 
Coles, 2001). Although there are methods to accomplish this, they are unsuited for unsupervised threshold estimations of model data. A common practice is thus to use the local $95 \%$ or $99 \%$ percentile.

We applied here the POT analysis as described in Gutjahr et al. (2016b) (Appendix A) and calculated the RLs for return periods of up to 20 years based on the three different time periods described above. As the threshold for the GPD, we used the local $95 p$ values from section 4.1 . We refer to this threshold as $u_{95}$ in the remainder of this manuscript. The scale $(\sigma)$ and shape $(\xi)$ parameters of the GPD (Equation A1) were fitted with maximum-likelihood estimation. Once a GPD is fitted to the sample data, RLs of any return period can be calculated (Equation A2).

Because we assume constant threshold over time, we performed parametric-bootstrapped $(n=1,000, \alpha=5 \%)$ Mann-Kendall trend tests (Mann, 1945) for $u_{95}$ to check whether this assumption is justified (section 5.1.2). Then, we performed parametric-bootstrapped $(n=1,000, \alpha=5 \%)$ Anderson-Darling goodness-of-fit tests (Choulakian and Stephens, 2001) to test whether the threshold exceedances follow the GPD (section 5.2.1). Finally, we analysed the effect of different thresholds and time periods onto the results (section 5.2.3).

The main focus is, however, on the comparison of the $\mathrm{RL}_{10}$, calculated from the overlapping period 2000/ 2001-2011/2012 of all data sets and the effect of different horizontal resolutions.

\section{5 | RESULTS}

\section{1 | Extreme wind indices}

\subsection{1 | Ninety-five percent percentiles (thresholds $\boldsymbol{u}_{95}$ )}

Figure 2 shows the thresholds $\left(u_{95}\right)$ for the POT method. The highest values $(\geq 20 \mathrm{~m} / \mathrm{s})$ across all data sets occur in the North Atlantic, in the Greenland, Icelandic and Norwegian (GIN) Seas, and along Greenland's southeast coast. Very high values ( $>26 \mathrm{~m} / \mathrm{s}$ ) occur over the Irminger Sea at Cape Farewell, offshore the Ammassalik Island, and in the Denmark Strait (Figure 2a). The values are slightly lower along Greenland's ice sheet margins and at the outlets of the Køge Bugt and Sermilik Fjord (Figure 2a). These extreme wind speeds are caused by the above described mesoscale wind systems of tip jets, barrier winds, katabatic winds, and plateau jets. High thresholds (up to $22 \mathrm{~m} / \mathrm{s}$ ) also occur in the Norwegian and Barents Sea, which are known for polar lows and strong marine cold air outbreaks (Kolstad, 2015; 2017).

In the western Arctic, the $95 p$ values are lower: about $14-18 \mathrm{~m} / \mathrm{s}$ in the Chukchi Sea at the entrance to the Bering Strait and in the Beaufort Sea close to the coast of Alaska. The $u_{95}$ values are much lower over wide parts of the central Arctic, and in a corridor stretching from the Canadian Archipelago to the Siberian coast (Figure 2a,b). By comparing the $u_{95}$ values of ERA-I (Figure 2b) with CCMPv2 over ocean (Figure 2a), it is clear that ERA-I does not adequately simulate tip jets and barrier winds. The differences are about $-4 \mathrm{~m} / \mathrm{s}$ in the North Atlantic and about $-7 \mathrm{~m} / \mathrm{s}$ at Cape Farewell and in the Denmark Strait. Note that some differences occur over land because of the interpolation onto the C15 grid. Further, ERA-I simulates too low thresholds in the GIN Seas and in the Barents Sea. The reason for this underestimation cannot be deduced from our analysis, it might be related to too weak or too less frequent polar lows or marine cold air outbreaks, but could also be related to the turbulence parameterization.

A comparison of the higher resolved models (Figure 2c-e) with ERA-I shows that both ASR models and C15 simulate higher thresholds in the North Atlantic and in the GIN Seas. Although most of the spatial structure is already captured by ASRv1 to first order, several deviations are simulated by ASRv2. For instance, ASRv2 and C15 reduce the area of high thresholds in the North Atlantic and confine it to Greenland's southeast coast. The reduction is stronger in ASRv2 than in C15, which still simulates high thresholds associated with westerly tip jets, reaching far over the Irminger Sea.

Another notable difference of ASRv2 and C15 is, however, the much higher thresholds simulated by ASRv2 in the area of the Greenland plateau jet and inland of Greenland's southeast coast. Particularly the discovered onshore extension of the tip jets at Cape Farewell (Moore et al., 2016) is visible (Figure 3d). However, it is difficult to judge whether these differences are an improvement, because CCMPv2 falls back to ERA-I over land.

Compared with ERA-I and CCMPv2, ASRv2 and C15 simulate higher thresholds in the Nares Strait. These are associated with the low-level jets (LLJ; Samelson and Barbour, 2008), which are most intense at the southern exit of the narrow Kennedy Channel and of the Smith Sound, which is the southern part of Nares Strait and connects the Kane Basin to the Baffin Bay. Both are known sites for polynya formation, in particular the climate relevant North Water Polynya (Barber et al., 2001). Although polynyas are parameterized (if at all) in ocean and sea-ice models, underestimating the LLJ in the Nares Strait contributes to a bias by underestimating the resulting turbulent fluxes. These results demonstrate that a horizontal resolution of $\leq 15 \mathrm{~km}$ is required to simulate these jets. A direct conclusion from this finding is that current global earth system models underestimate climate relevant air-sea fluxes in this area.

Besides the areas with the highest thresholds, the models differ in other areas as well. For instance, at the Hall and Cumberland Peninsulas, which are parts of Baffin Island in the Canadian Archipelago, higher thresholds were simulated by ASR and C15 compared to ERA-I. Particularly in ASRv2, the $u_{95}$ values exceed $28 \mathrm{~m} / \mathrm{s}$ and are slightly less in $\mathrm{C} 15$. According to the spatial structure simulated by $\mathrm{C} 15$, 
(a)

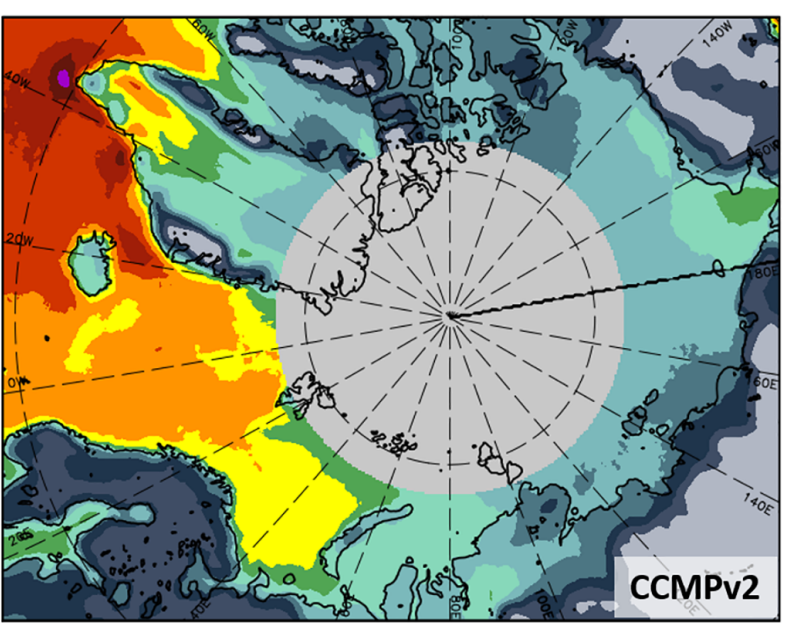

(c)

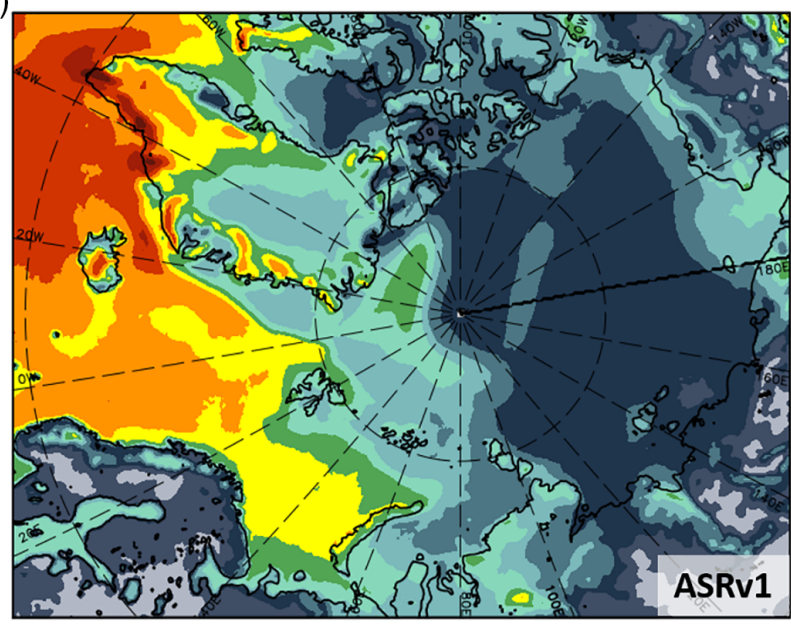

(e)

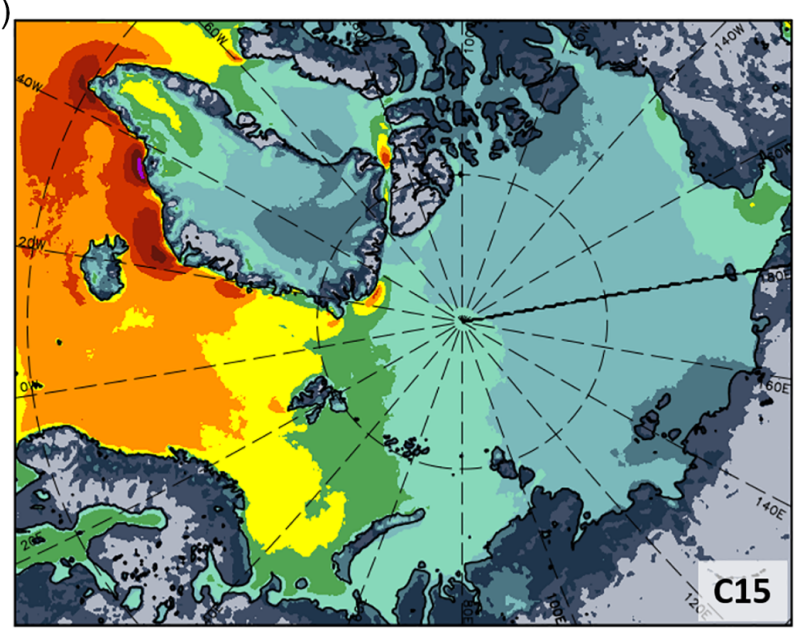

(b)

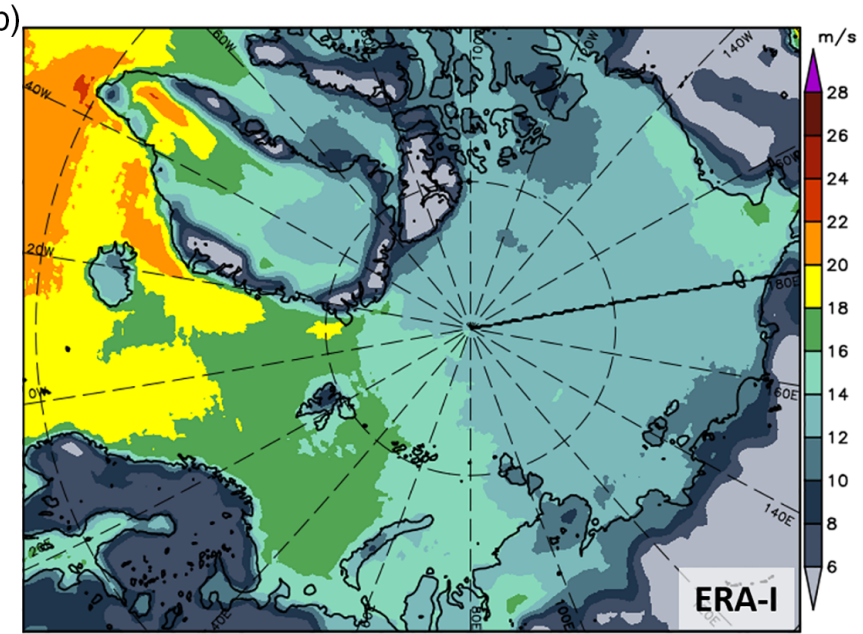

(d)

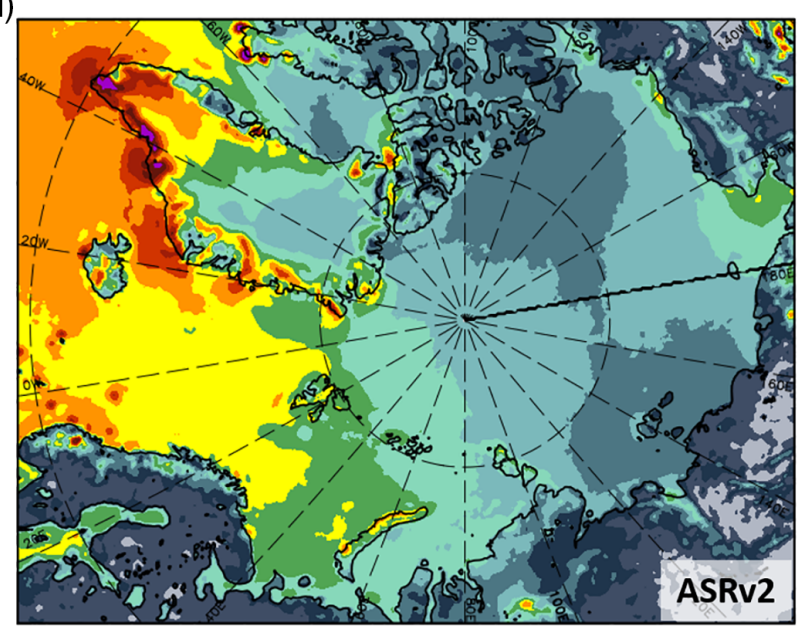

(f)

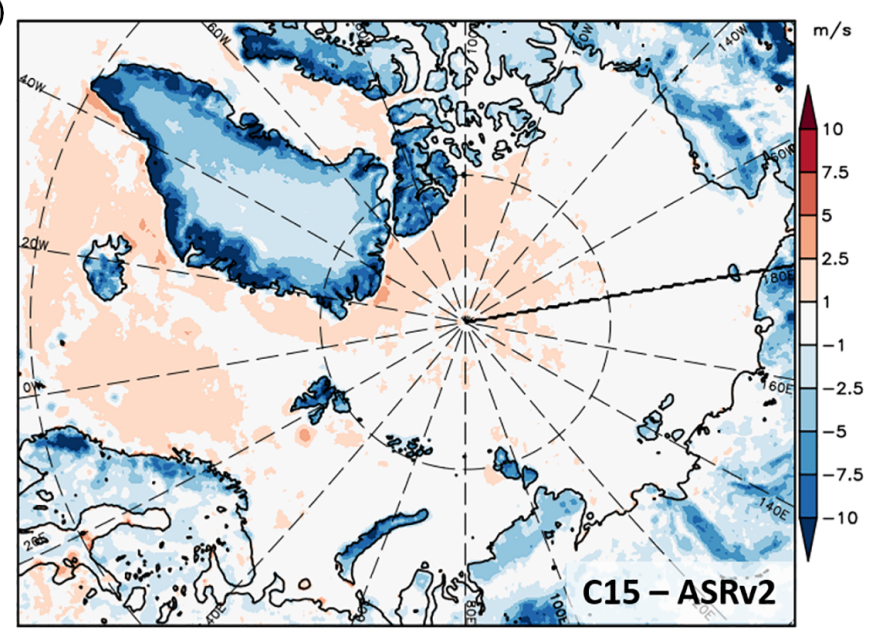

FIGURE 2 The thresholds $u_{95}$ for the POT method defined as the local 95\% (95p) percentile of daily maximum wind speed $\left(U_{10 \mathrm{x}}\right)$ in the winter (NovemberApril) 2000/2001-2011/2012 for (a) CCMPv2, (b) ERA-I, (c) ASRv1, (d) ASRv2, (e) C15, and (f) C15 minus ASRv2. No data (grey shaded area in (a)) was available for CCMPv2 north of $78^{\circ} \mathrm{N}$ [Colour figure can be viewed at wileyonlinelibrary.com]

these high values correspond to the northeasterly tip jets described by Hanesiak et al. (2013).

ASRv1 is not able to resolve tip jets along Greenland's northeast coast, in particular at Cape Morris Jesup and Nordøstrundingen. Although there is no data from CCMPv2, even ERA-I shows a typical tip jet pattern at Nordøstrundingen. In contrast, ASRv2 and C15 simulate tip jets there and also at Cape Torbin, located on the exit of the Scoresby Sund, and at Hudson Land, which belongs to the eastern part of Kong Christian X Land north of the Scoresby Sund. Further, both models capture the tip jets at Svalbard's South Cape, indicated by high thresholds, although they are slightly higher in C15. An exception is the Nova Zemlya bora. Both ASR models show higher thresholds along the 
northwest coast of Nova Zemlya compared with ERA-I, but also in comparison with C15. Both, ASRv2 and C15, simulate slightly higher thresholds in the Chukchi and Beaufort Sea compared with the coarser data sets. ASRv1 simulates weaker thresholds over sea ice; in particular in the area from the Canadian Archipelago via the central Arctic to the Siberian coast. This underestimation improves in ASRv2. The differences might be caused by changes in the sea ice module in ASRv2.

These results indicate that by increasing the horizontal resolution of an RCM, the extreme winds enhance in particular over the ocean close to Greenland's southeast coast, in particular in the Irminger Sea, in the Denmark Strait, and in the Nares Strait. Over land, the results are not consistent. A horizontal resolution of at least $15 \mathrm{~km}$ is required to capture the mesoscale phenomena.

\subsection{2 | Trend analysis of the thresholds}

Because we assume a constant thresholds $u_{95}$ for the POT method, we performed Mann-Kendall trend tests $(\alpha=5 \%)$ on winter half-year averaged $95 \%$ percentiles of ERA-I and C15 for 1979/1980-2015/2016 and 2000/2001-2011/2012. Figure A3a-d shows the resulting $p$ values.

Significant trends resulted only for about 5.12\% (3.75\%) of the domain for ERA-I (C15) based on the winter period 2000/2001-2011/2012 and slightly less based on the winter period 1979/1980-2015/2016.

Areas with significant trends based on the short period are the Kara and Laptev Sea. In both areas slight positive trend of about +0.1 to $+0.2 \mathrm{~m} \mathrm{~s}^{-1}$ year $^{-1}$ were found (not shown). Based on the longer period (Figure A3c,d), however, the pattern is more random. Given that we use a tradeoff for the threshold and that we assume it to be constant, an error of about $5 \%$ is acceptable. In contrast to warming trends of the near-surface temperature in the Arctic (Serreze and Barry, 2011; Bromwich et al., 2017; Kohnemann et al., 2017), this analysis suggests that the $95 \%$ percentiles of wind speed show no trends. A similar result was found by Spreen et al. (2011) for winter wind speeds (October-May) 1992-2009 from four global reanalyses data sets (except for the Central Arctic) and by Kwok et al. (2013) for NCEP winds (1982-2009). However, Hakkinen et al. (2008) attributed an increase of sea ice drift to a positive trend in NCEP wind stress (1948-2006) over the last 50 years, which is caused by a northward shift of the storm track.

\subsection{3 | Strong gale and hurricane days}

The occurrence of strong gale days $\left(S_{g}\right)$ is clearly distinctive offshore of Greenland's southeastern coast in the CCMPv2 data (Figure 3a), particularly at Cape Farewell, over the Irminger Sea, and in the Denmark Strait. On average, wind speeds above $20.5 \mathrm{~m} / \mathrm{s}$ occur on more than 20-30 days per winter; at Cape Farewell even on up to 50 days. In the Labrador Sea, Greenland Sea, Norwegian and Barents Sea the $S_{g}$ index is about 5-15 days lower, and almost no strong gales are simulated in the remainder of the Arctic. ERA-I is not able to resolve these high wind speeds and underestimates $S_{g}$ considerably (Figure 3b); most severely at Cape Farewell with about 20 days too few strong gale days on average.

Compared with ERA-I, the ASR models (Figure 3c,d) considerably improve the number of strong gale days over the North Atlantic. Yet compared to CCMPv2, both ASR models still underestimate the frequencies at Cape Farewell. But C15 simulates a similar number of $S_{g}$ as CCMPv2. In contrast to the previous finding, only ASRv2 reduces the area with high $S_{g}$ frequencies over the North Atlantic.

A notable difference to ASRv2 is the much increased $S_{g}$ frequency in the Denmark Strait by C15. Although both models simulate a similar threshold here (see section 5.1.1), C15 simulates more often strong gales. Consistent with the higher thresholds over Greenland's southeast coast, ASRv2 simulates also higher frequencies of $S_{g}$. The highest frequency (up to 40) in ASRv2 is at the onshore extension of the tip jets at Cape Farewell.

Another consistent feature of ASRv2 and C15 is the higher $S_{g}$ frequencies (about 20-25 days) at the outlet of Smith Sound in the Nares Strait, which are not present in coarser models. Although there is no data from CCMPv2, the consistent results indicate that a horizontal resolution of at least $15 \mathrm{~km}$ is required to resolve this wind system. Striking are also moderately frequent $S_{g}$ at Cape Morris Jesup, Nordøstrundingen (northeast Greenland), and at Svalbard's South Cape.

The average number of hurricane days $\left(S_{h}\right)$ per winter rarely exceed 1 for most parts of the Arctic (Figure A1). Over most of the North Atlantic, hurricane intensities occur only every other winter. Higher frequencies up to 3 days per winter occur only in areas with already frequent strong gales, such as offshore Cape Farewell and the Ammassalik Island (Figure A1a). ERA-I does not capture the hurricane intensities at these sites, and simulates almost none over the North Atlantic (Figure A1b). ASRv2 underestimates $S_{h}$ offshore Cape Farewell, but simulates up to four hurricane days onshore Cape Farewell and Greenland's southeast and southwest coast (Figure A1c). Noteworhty are hurricane intensities every other winter at the westcoast of Novaya Zemlya, which are associated with the bora. C15 simulates as well too few hurricane days offshore Cape Farewell and over the North Atlantic (Figure A1d), but captures them well offshore the Ammassalik Island.

\section{2 | Return levels of extreme wind speed}

The POT method was applied to time series of daily maximum $10 \mathrm{~m}$ wind speed $\left(U_{10 \mathrm{x}}\right)$ of all data sets listed in Table 1 . We set the thresholds $u_{95}=95 p$ (Figure 2). We selected five sites (A-E) of different wind regimes in the vicinity of Greenland (see Figure $1 \mathrm{~b}$ for their locations) to exemplify inter-model differences of return levels (RLs), calculated for return periods up to 20 years, and of their associated uncertainties. 
(a)

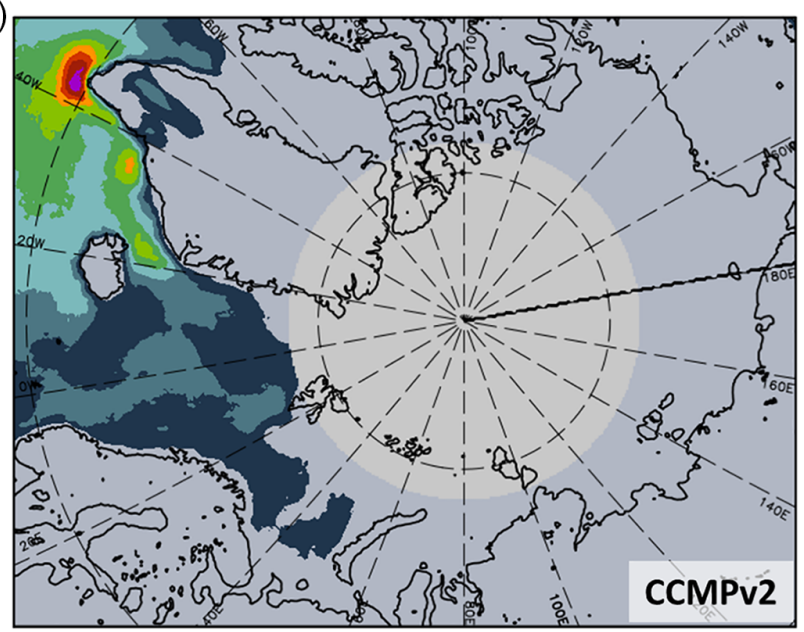

(c)

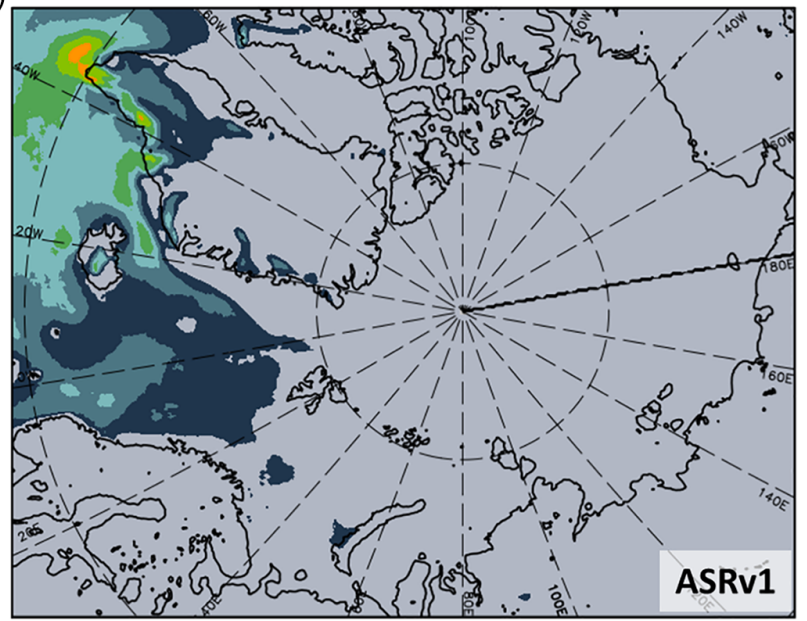

(e)

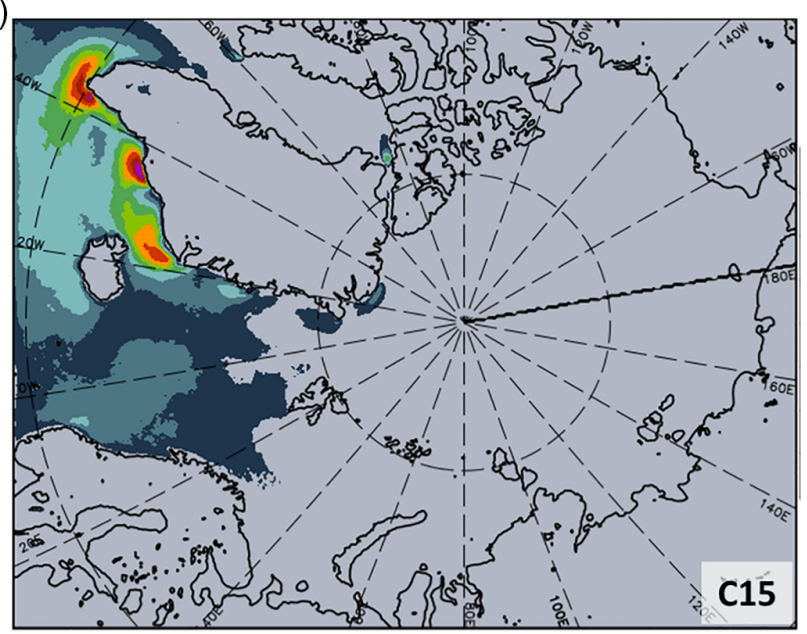

(b)

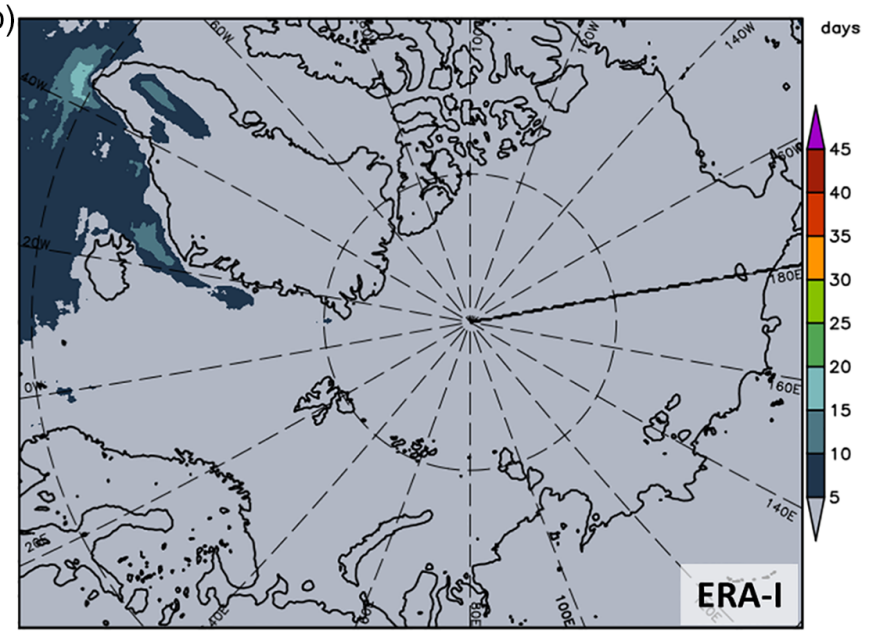

(d)

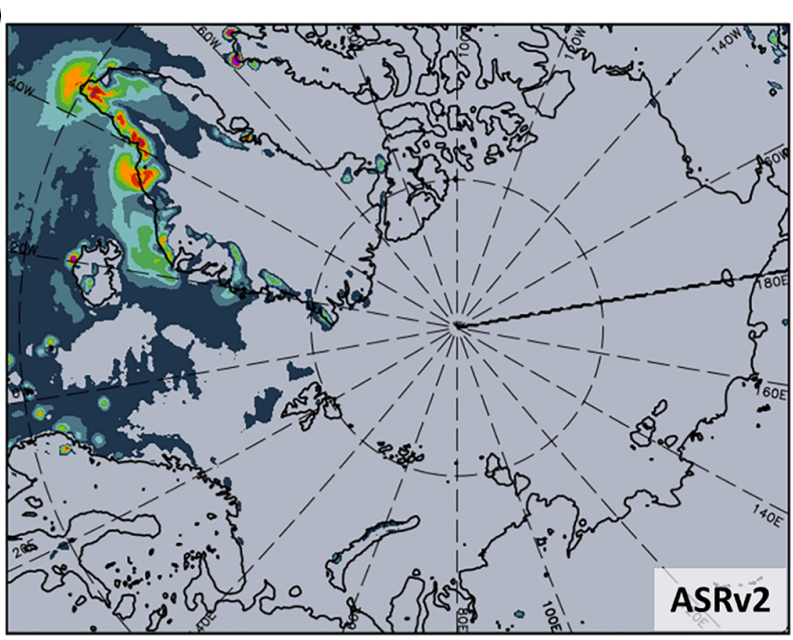

(f)

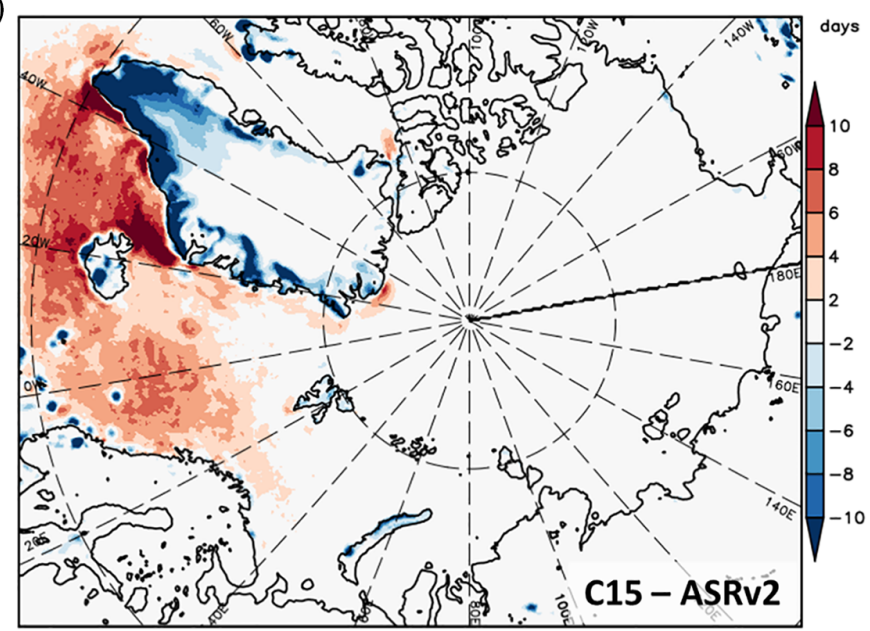

FIGURE 3 Average number of strong gale days $\left(S_{g}\right)$ with $>20.5 \mathrm{~m} / \mathrm{s}$ per winter in the period 2000/2001-2011/2012 (November-April) for (a) CCMPv2, (b) ERA-I, (c) ASRv1, (d) ASRv2, (e) C15, and (f) C15 minus ASRv2. No data was available for CCMPv2 north of $78^{\circ} \mathrm{N}$ (grey shaded area in (a)) [Colour figure can be viewed at wileyonlinelibrary.com]

\subsection{1 | GPD goodness-of-fit tests}

Accepting the 95\% percentile as the threshold, we performed parametric-bootstrapped $\quad(n=1,000) \quad$ Anderson-Darling goodness-of-fit tests $(\alpha=5 \%)$ for the fitted GPDs. For C15 the fitted GPDs were rejected $(p<.05)$ only for a small portion of the domain (4.20\%) (Figure A3f), which we think is acceptable. The rejections further obey no coherent spatial pattern.

\subsection{2 | Ten-year return levels based on 2000/2001-2011/2012}

Maps of the 10-year return levels $\left(\mathrm{RL}_{10}\right)$ are shown in Figure 4. In comparison to the thresholds (Figure 2), the 
$\mathrm{RL}_{10}$ show much more spatial variability over the North Atlantic, in the Irminger Sea, and in the GIN Seas.

Very high $\mathrm{RL}_{10}$ of $\geq 38 \mathrm{~m} / \mathrm{s}$ result for the same areas that already showed the highest thresholds $\left(u_{95}\right)$ and most frequent strong gale days $\left(S_{g}\right)$. These are the North Atlantic, the Irminger Sea, the GIN Seas, the Barents Sea, and the southeastern coast of Greenland. Compared to CCMPv2
(Figure 4a), ERA-I underestimates the $\mathrm{RL}_{10}$ over ocean, in particular in the North Atlantic and over the Irminger Sea. A dipole structure of the westerly and easterly tip jets is present in CCMPv2, with $\mathrm{RL}_{10}$ values of almost $40 \mathrm{~m} / \mathrm{s}$. This dipole structure is absent in ERA-I, so that the $\mathrm{RL}_{10}$ are about $10 \mathrm{~m} / \mathrm{s}$ lower; particularly for the westerly tip jets over the Irminger Sea. Considerably lower $\mathrm{RL}_{10}$ values result also (a)

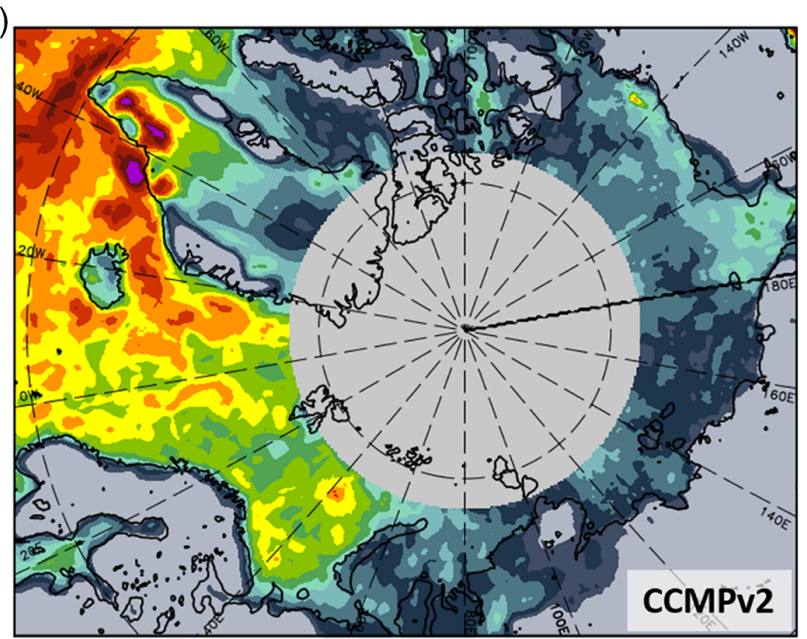

(c)

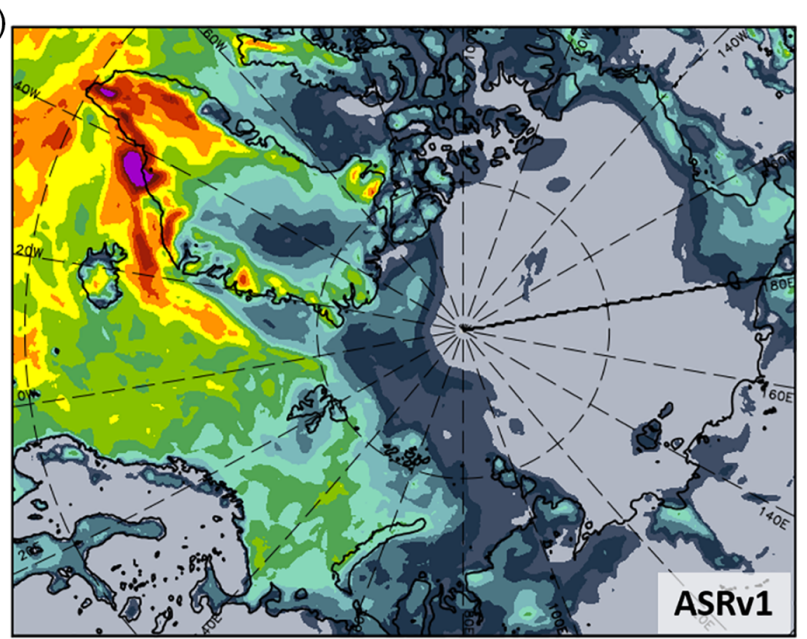

(e)

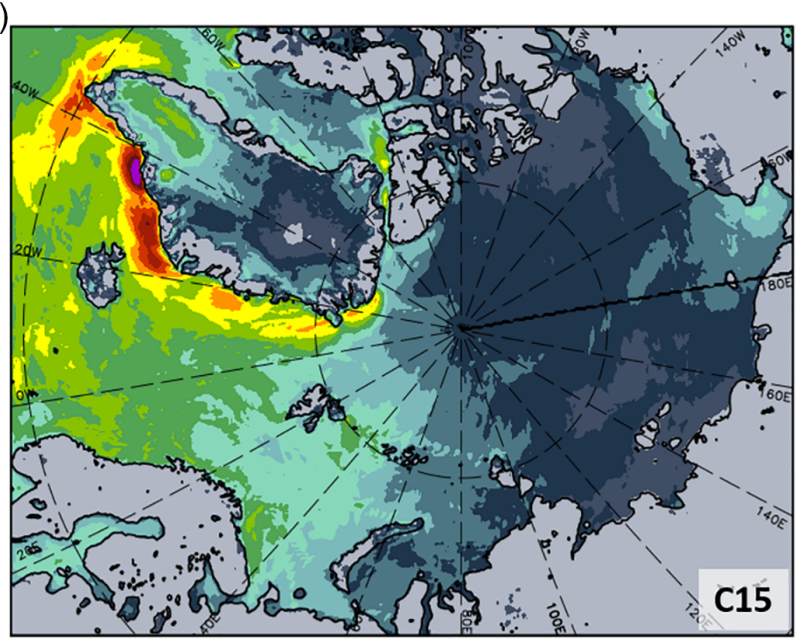

(b)

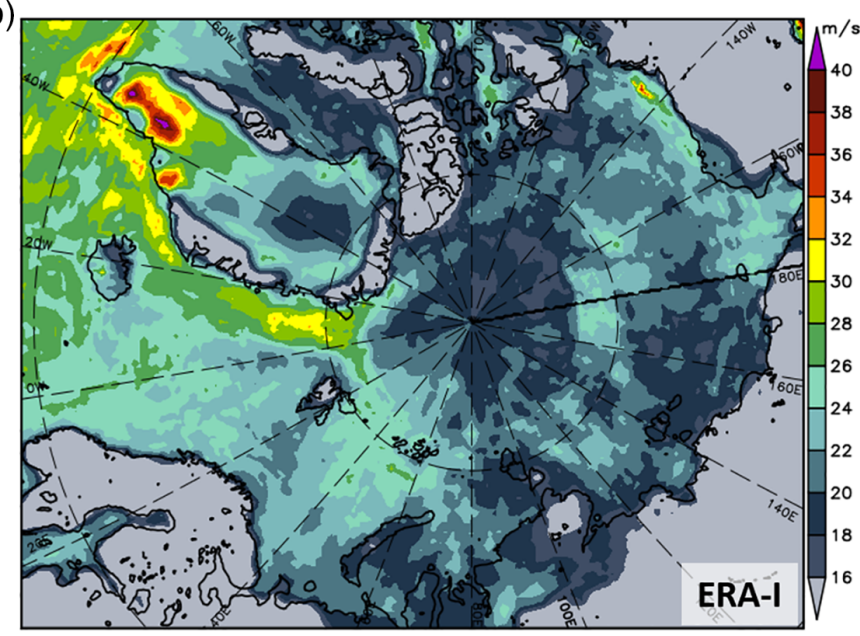

(d)

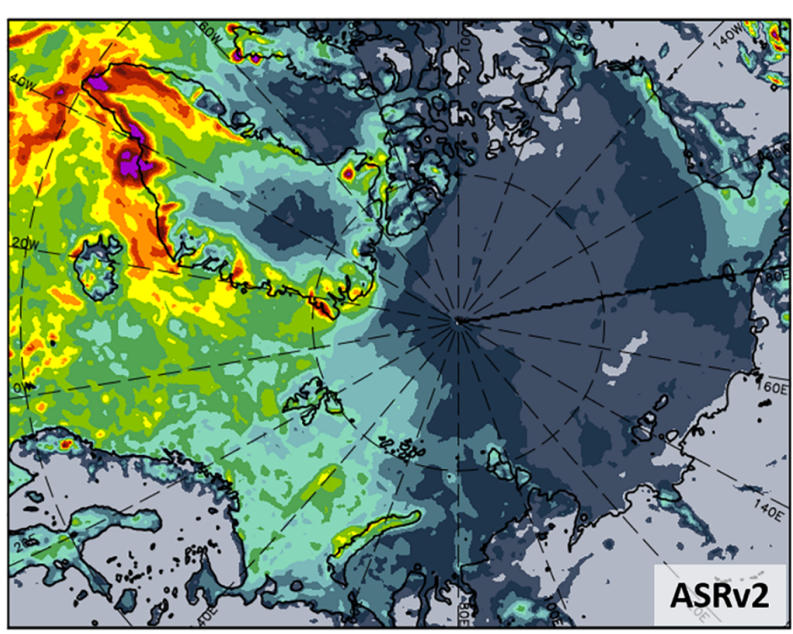

(f)

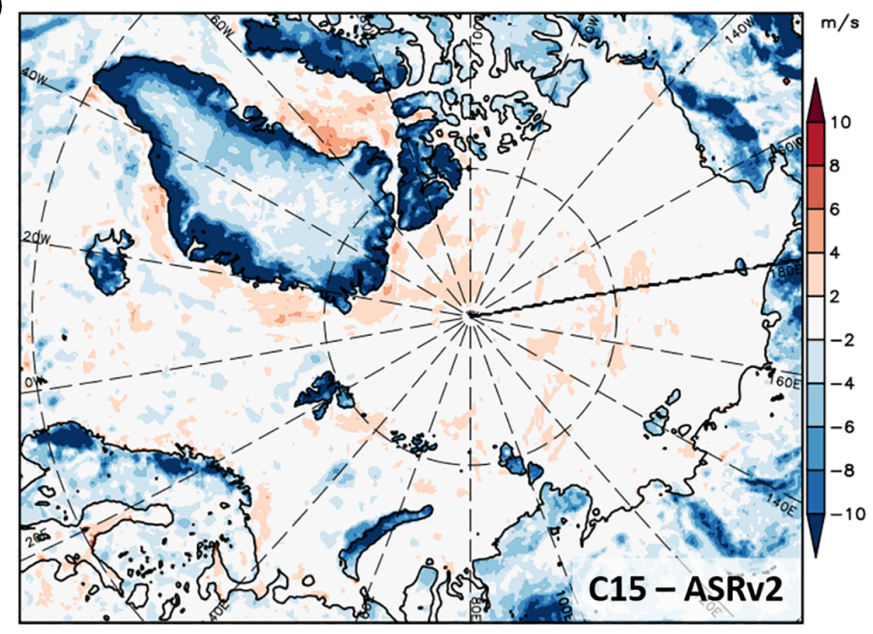

FIGURE 4 Estimated 10-year return levels $\left(\mathrm{RL}_{10}\right)$ of $10 \mathrm{~m}$ daily maximum wind speed $\left(U_{10 \mathrm{x}}\right)$ from the POT method for (a) CCMPv2, (b) ERA-I, (c) ASRv1, (d) ASRv2, (e) C15, and (f) C15 minus ASRv2. The estimations are based on the winter half-years 2000/2001-2011/2012 (November-April). No data was available for CCMPv2 north of $78^{\circ} \mathrm{N}$ (grey shaded area in (a)) [Colour figure can be viewed at wileyonlinelibrary.com] 
offshore the Ammassalik Island, where $40 \mathrm{~m} / \mathrm{s}$ are estimated from CCMPv2. Almost no signal of high return levels result for the Labrador Sea, the Denmark Strait, or the GIN Seas.

The higher resolved ASR models and C15 are able to resolve the mesoscale wind systems and show the dipole structure of the tip jets at Cape Farewell. Although the resulting $\mathrm{RL}_{10}$ are still underestimated by about $5 \mathrm{~m} / \mathrm{s}$, the usage of high resolved models improve the spatial structure considerably. Outside the tip jet cores, the $\mathrm{RL}_{10}$ are only about $2 \mathrm{~m} / \mathrm{s}$ lower, for instance in the central Irminger Sea. Both ASR models and $\mathrm{C} 15$ capture the very high $\mathrm{RL}_{10}$ values offshore the Ammassalik Island, which is a clear improvement. Although improved, the $\mathrm{RL}_{10}$ of the higher resolved models are still too low over the Norwegian and Barents Sea. This indicates that either too few or to weak polar lows or extra-tropical cyclones are simulated by ASR and C15. An exception is the Fram Strait, where ASR and C15 generally capture the high return levels, but with notable deviations. Based on ASRv1, high $\mathrm{RL}_{10}$ result only over open ocean off the sea ice edge (not as dominant in ASRv2), but already over sea ice in $\mathrm{C} 15$, which seems more realistic compared to CCMPv2. High return levels over the sea ice seem reasonable where marine cold air outbreaks occur frequently (Kolstad, 2017).

High $\mathrm{RL}_{10}(>30 \mathrm{~m} / \mathrm{s})$ result from $\mathrm{C} 15$ also for the previously identified tip jets of Nordøstrundingen and Cape Morris Jesup in northeast Greenland. These tip jets are absent in ASRv1 but captured by ASRv2; although they do not extend as far offshore as in C15.

Two maxima of $\mathrm{RL}_{10}$ with $30 \mathrm{~m} / \mathrm{s}$ result from ASRv2 and C15 for the LLJ in the Nares Strait at the exit of the Kennedy Channel and Smith Sound (Figure 4d-e). Again, these improvements are important for air-sea interactions for the North Water polynya.

ASRv2 further enhances the $\mathrm{RL}_{10}$ associated with the Novaya Zemlya bora (Figure 4d); onshore as well as offshore. The bora is usually strongest for south to southeasterly flow direction that can lead to a downslope acceleration in the lee of the 120-140 km wide Novaya Zemlya archipelago. Details of the mechanisms were given by Moore (2013) based on ASRv1. Compared to ASRv1, the $\mathrm{RL}_{10}$ associated with the bora are stronger in ASRv2. Neither ERA-I nor C15 show a signal of high $\mathrm{RL}_{10}$ values in that area. The absent signal of the bora in $\mathrm{C} 15$ might be related to too weak downslope acceleration. In ERA-I it might be related to the too coarse horizontal resolution. Both ASR models simulate a secondary maximum $(28 \mathrm{~m} / \mathrm{s})$ over the central Barents Sea that was described by Moore (2013) and is also present in CCMPv2 (Figure 4a). Again, ERA-I and C15 also underestimate this maximum.

Considerably higher $\mathrm{RL}_{10}$ result from ASR and $\mathrm{C} 15$ for the tips of the Hayes peninsula in northwest Greenland. Here trapped lee-waves and tip jets generate strong near-surface winds (Moore et al., 2016). The $\mathrm{RL}_{10}$ rarely exceed $22 \mathrm{~m} / \mathrm{s}$ in the Chukchi and Beaufort Sea and are much lower for large parts over sea ice. Noteworthy is a slight increase of $\mathrm{RL}_{10}$ in ASRv2 and C15 at Severnaya Zemlya and in the Vilkitsky Strait, which separates this island group from the Siberian coast. Recent simulations with CCLM for this area confirmed that increasing the horizontal resolution (down to $5 \mathrm{~km}$ ) enhances the channelling effect at the eastern outlet of Vilkitsky Strait (Janout et al., 2017).

Over land, maxima are associated with the Greenland plateau jet and with katabatic winds in the Køge Bugt Fjord and in the Sermilik Fjord. The difference of C15 to ASRv2 (Figure 4f) again shows underestimations of C15 along Greenland's coasts and over its ice sheet, but also in other orographic regions such as in Svalbard or in the Canadian Archipelago. These underestimations can be as strong as $-10 \mathrm{~m} / \mathrm{s}$. Over ocean and over sea ice C15 is comparable with ASRv2. Interestingly, the $\mathrm{RL}_{10}$ from ASRv2 are higher over sea ice in the Fram Strait compared with ASRv1, which results in a sharp gradient at the sea ice edge. In particular at Cape Morris Jesup and Nordøstrundingen where tip jets occur frequently. Again, the higher resolved models (ASRv2 and C15) lead to higher RLs estimates also in the Nares Strait due to a better representation of the LLJ. The $\mathrm{RL}_{10}$ are about $30 \mathrm{~m} / \mathrm{s}$ at the southern exit of the Kennedy Channel and of the Smith Sound.

These results indicate that although a horizontal resolution of $30 \mathrm{~km}$ captures most of the intensity and spatial pattern of extreme wind speeds, only with a horizontal resolution of at least $15 \mathrm{~km}$ important mesoscale wind systems, such as the LLJ in the Nares Strait, can be resolved. However, even then small-scale wind systems remain unresolved.

\subsection{3 | Sensitivity of RLs to the chosen period and threshold}

To analyse the uncertainty of the RL estimates based on the winter period 2000/01-2011/12 from the previous section, we compared the RLs with the estimates based on the longer winter-period 1979/1980-2015/2016. Figure 5a-c shows the differences for $\mathrm{RL}_{10}$. For most parts of the Arctic, except Siberia and Baffin Bay, the $\mathrm{RL}_{10}$ of CCMPv2 based on the shorter period are slightly overestimated by about $1-4 \mathrm{~m} / \mathrm{s}$ (Figure 5a). The domain averaged difference for CCMPv2 is $0.5 \mathrm{~m} / \mathrm{s}$. At some locations, for example over the Irminger Sea or in the Barents Sea, the overestimation is larger than $5 \mathrm{~m} / \mathrm{s}$. Too low winds in CCMPv2 may be a result of the variable satellite sensors used to derive wind speeds within these periods. In contrast, for ERA-I and C15 (Figure 5b,c) the $\mathrm{RL}_{10}$ are slightly underestimated for large parts of the Arctic (domain averaged differences are -0.5 and $-0.4 \mathrm{~m} / \mathrm{s}$, respectively). It is interesting that the downscaling of ERA-I by $\mathrm{C} 15$ leads to smaller differences particularly north of Greenland and for the Siberian and Beaufort Seas. Differences of the $95 \%$ percentile for C15 are very small and differences of the threshold for $\mathrm{C} 15$ (Figure 5d) are even less; 
they range from $-1 \mathrm{~m} / \mathrm{s}$ in the GIN seas to $+1 \mathrm{~m} / \mathrm{s}$ in the central Arctic.

We further analysed how sensitive the return levels are to the choice of the threshold: local $95 \%$ or $99 \%$ percentiles. The $\mathrm{RL}_{10}$ differences based on $\mathrm{C} 15$ using $95 \%$ or $99 \%$ are very small and range between $\pm 0.5 \mathrm{~m} / \mathrm{s}$ (Figure A3e). Given these results, the estimation of RLs based on the period 2000/2001-2011/2012 using the local 95\% percentiles as thresholds is justified.

\subsection{4 | Return levels of extreme wind speed at sites}

For a more detailed analysis, we show the estimated return levels for five sites (A-E; see Figure 1b) as continuous curves up to the 20 year return period (Figure 6). These return level curves were constructed from results of specific grid boxes that were chosen to represent different wind regimes in the vicinity of Greenland. The return level curves are based on the winter half-years 2000/2001-2011/2012.

Site A (Figure 6a) is located in the Irminger Sea where the highest $\mathrm{RL}_{10}$ were estimated (section 5.2.2) and thus the return level curves reach values $\geq 40 \mathrm{~m} / \mathrm{s}$ for the 10 - and 20-year return periods. The return level curves of all models are close to CCMPv2, except ERA-I. The RLs of ERA-I are about $10 \mathrm{~m} / \mathrm{s}$ lower across all considered return periods, which can also be seen from Table 2 that further lists the estimated parameters of the GPD for all sites. This example demonstrates the benefit from high-resolution atmospheric models in the Arctic. The blue crosses show the explicitly simulated extreme wind speeds by $\mathrm{C} 15$ in the winter half-years 2000/2001-2011/2012, whereas the red points show the simulated extremes by $\mathrm{C} 15$ for all winter half-years 1979/1980-2015/2016. If the blue crosses are considered as a sample out of the true population of extreme winds (red dots), then the shorter period gives sufficient RL estimates as both, points and return level curves, are close by.

The $95 \%$ confidence intervals based on the short period are asymmetrical and they include the $\mathrm{C} 15$ estimates based on the long period (red dots). Similar well estimations result for the other sites (Figure 6b-d) and thus support our generalization from (Figure 5c). The shape parameter $\xi$ is negative for all data sets, so that the analysis suggests that return level
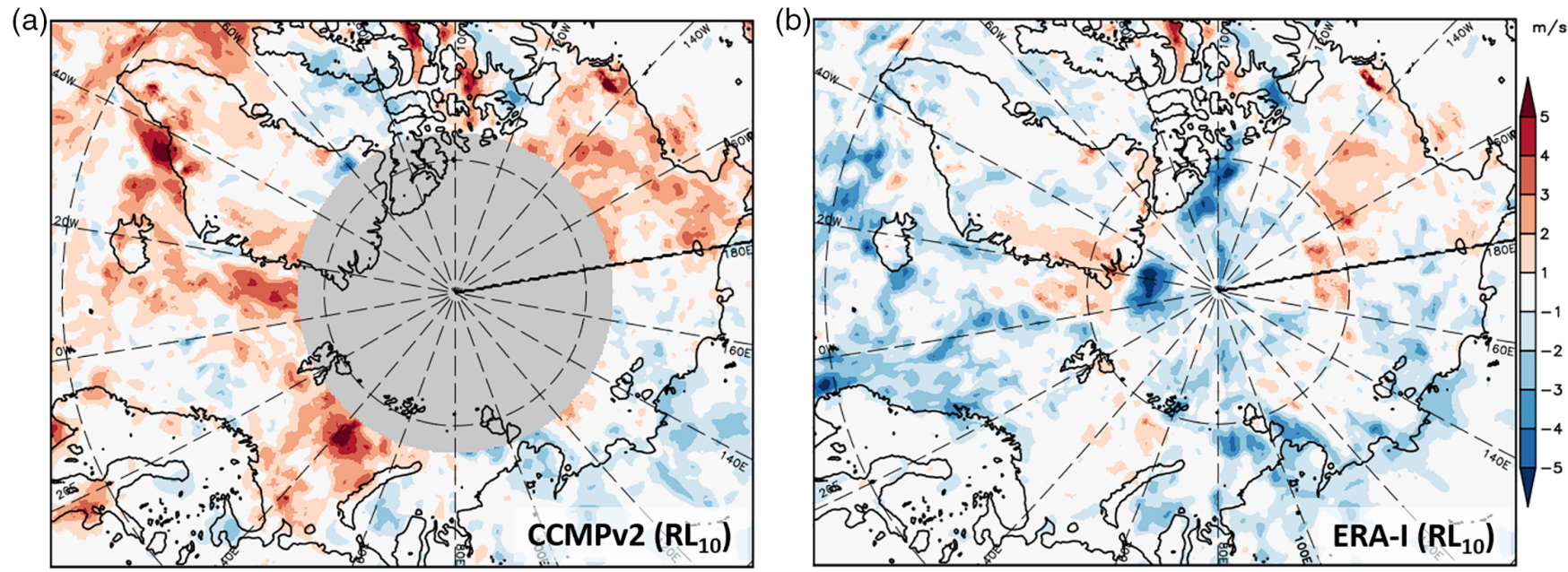

(c)

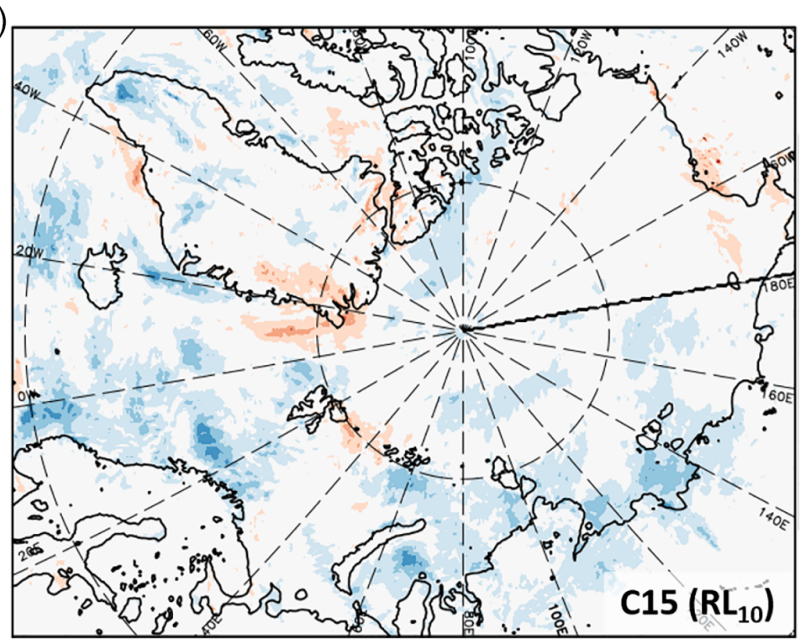

(d)

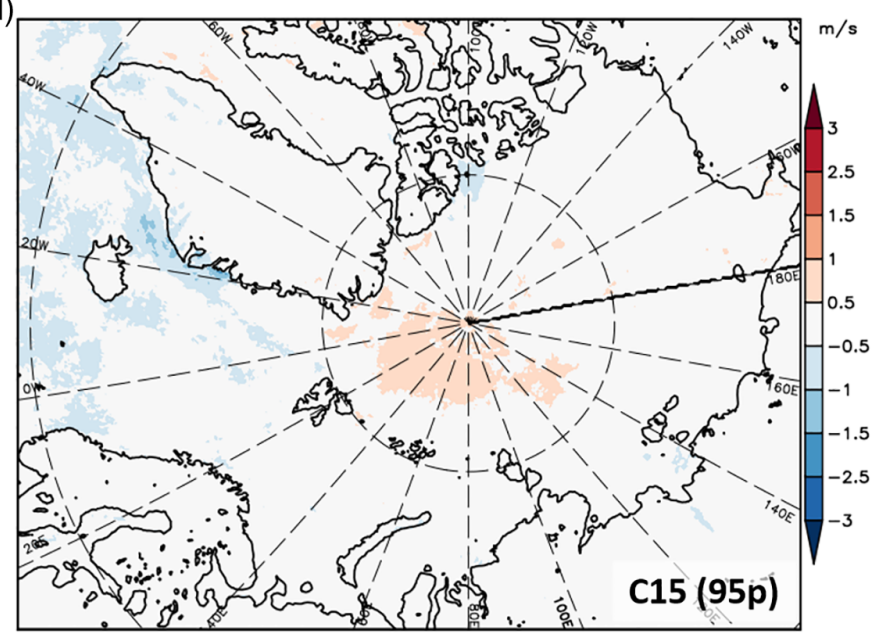

FIGURE 5 Differences of estimated 10-year return levels $\left(\mathrm{RL}_{10}\right)$ of $10 \mathrm{~m}$ daily maximum wind speed $\left(U_{10 \mathrm{x}}\right)$ from the POT method for (a) CCMPv2 (2000-2012)-CCMPv2 (1987-2016), (b) ERA-I (2000-2012)-ERA-I (1979-2016), (c) C15 (2000-2012)-C15 (1979-2016), and (d) differences of the 95\% percentiles (95p) of C15 (2000-2012)-C15 (1979-2016). No data was available for CCMPv2 north of $78^{\circ} \mathrm{N}$ (grey shaded area in (a)) [Colour figure can be 
(a)

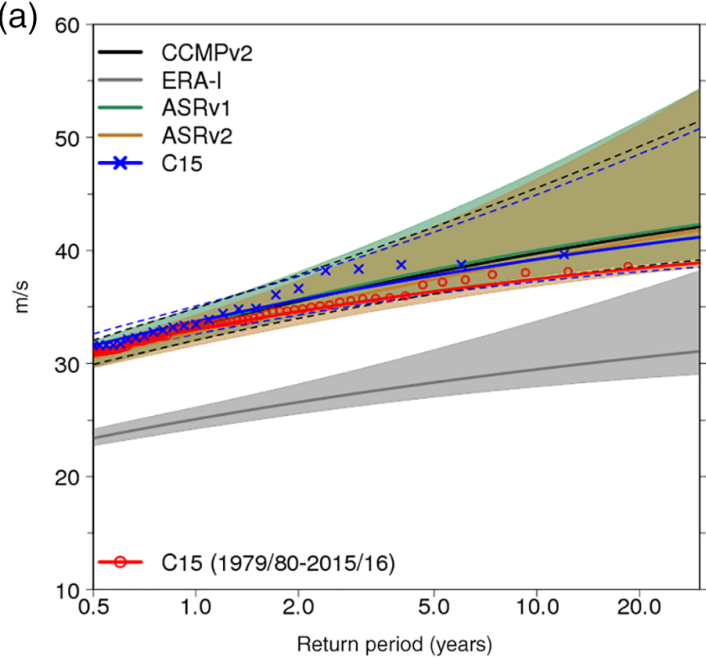

(d)

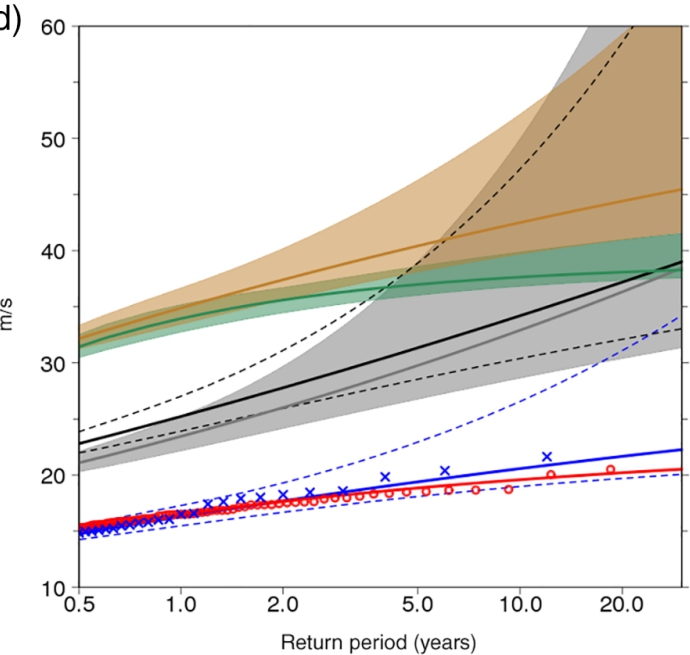

(b)

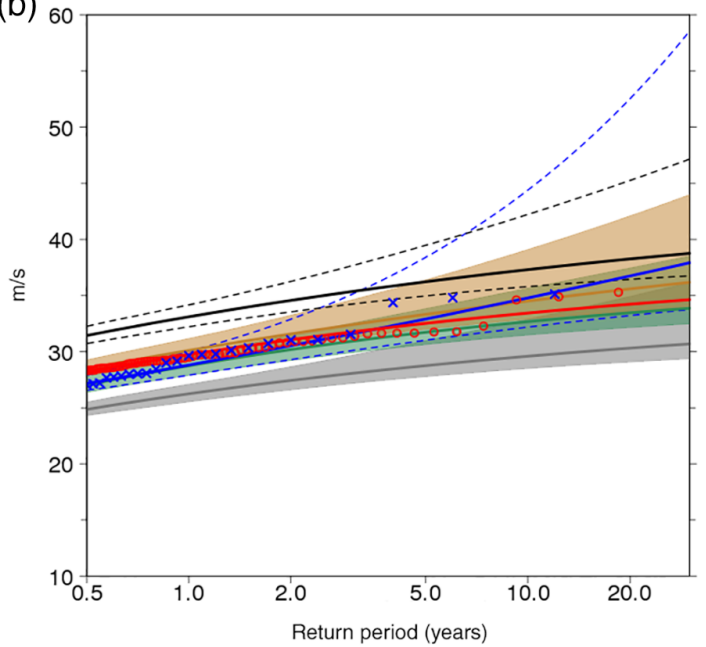

(e)

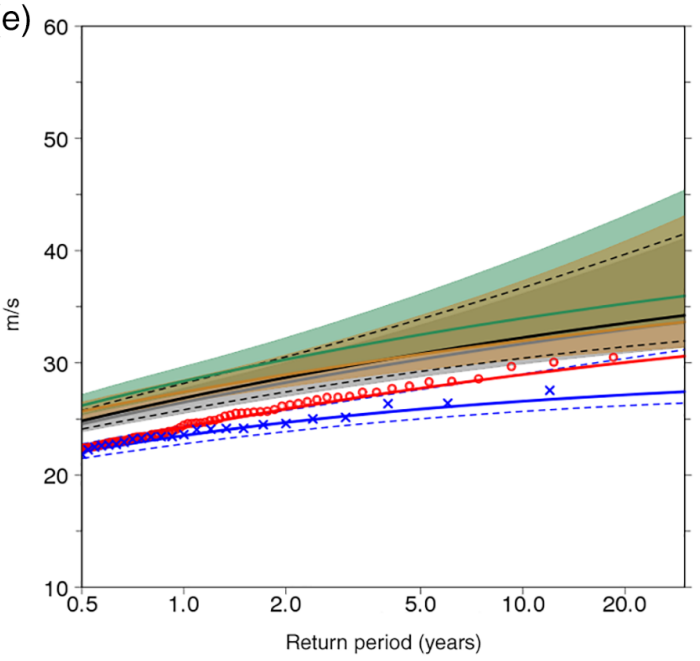

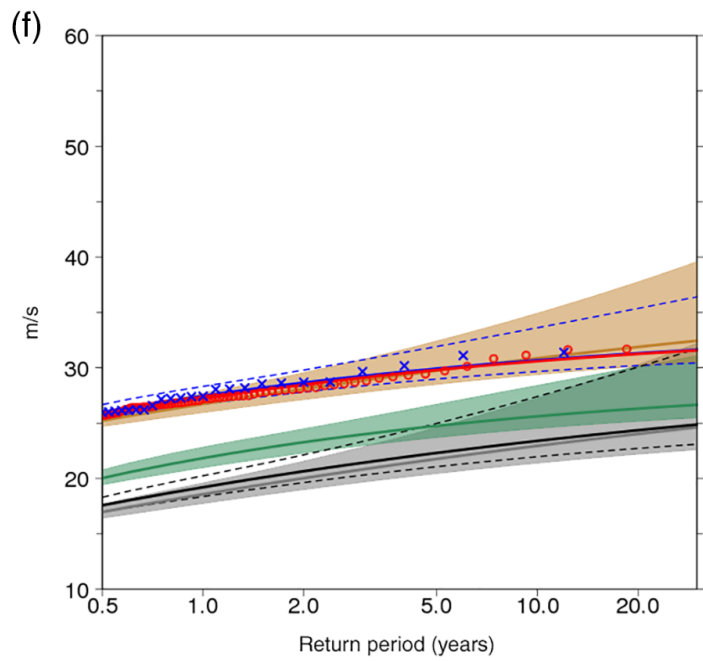

FIGURE 6 Return level curves of daily maximum $10 \mathrm{~m}$ wind speed $\left(U_{10 \mathrm{x}}\right)$ in winter (November-April) and the $95 \%$ profile log-likelihood confidence intervals (shaded colours) resulting from the POT method at the five sites: (a) A: Irminger Sea (barrier winds), (b) B: Cape Farewell (westerly tip jets), (c) C: Køge Bugt Fjord (katabatic flows), (d) D: Greenland plateau jet, and (e) E: Nares Strait (low-level jet). See Figure 1b for their locations. The fitting of the GPD distribution was based on the winter half-years 2000/2001-2011/2012 (November-April) for CCMPv2, ERA-I, ASRv1, and C15. The blue points show the extremes simulated by C15 based on 1979/1980-2015/2016 and the red crosses based on 2000/2001-2011/2012. An overview of the fitted parameters with their profile log-likelihood 95\% confidence intervals are given in Table 2 [Colour figure can be viewed at wileyonlinelibrary.com]

curves would reach asymptotically a maximum for longer return periods. However, because almost all the confidence intervals of $\xi$ include zero, a Gumble type distribution might also be justified. A value of zero for $\xi$ would result in more conservative estimates for higher return levels (Holmes and Moriarty, 1999). 
Site B (Figure 6b) is located offshore of Cape Farewell in the regime of westerly tip jets. The difference between the models is not as strong as for site A, but ERA-I again produces lower RLs across all return periods, compared with the higher resolved models ASR and C15. However, all models underestimate the RLs compared with CCMPv2. The shape parameter is again negative for most models (Table 2), with a slightly positive value for $\mathrm{C} 15$, causing wider confidence intervals.

For site C (Figure 6c) over the Køge Bugt Fjord there is a considerable difference between ASR and C15. While the return level curves of ERA-I and CCMPv2 are close-by (CCMPv2 falls back to ERA-I over land), C15 produces much lower RLs, whereas both ASR models produce much higher RLs (up to $+10 \mathrm{~m} / \mathrm{s}$ ), with higher values from ASRv2. Enhanced RLs compared with ERA-I might be expected because of the higher resolution, but the

TABLE 2 Maximum-likelihood estimated parameters of the GPD distribution with the POT method at five sites with different wind regimes (see the location of the five sites (A-E) in Figure 1b). Thereby $u 95$ denotes the threshold ( $95 p$ values) given in $\mathrm{m} / \mathrm{s}, \sigma$ the scale, and $\xi$ the shape parameter of the GPD. $\mathrm{RL}_{10}$ is the 10-year return level $(\mathrm{m} / \mathrm{s})$. The $95 \%$ profile log-likelihood (PLL) intervals of $\xi$ and $\mathrm{RL}_{10}$ are given in brackets

\begin{tabular}{|c|c|c|c|c|}
\hline Data set & $u 95$ & $\sigma$ & $\xi$ & $\mathbf{R L}_{10}$ \\
\hline \multicolumn{5}{|c|}{ Site A: Irminger Sea (barrier winds) } \\
\hline CCMPv2 & 25.5 & 4.53 & $-0.15[-0.33,0.08]$ & $39.8[37.5,45.5]$ \\
\hline ERA-I & 20.0 & 3.09 & $-0.16[-0.35,0.10]$ & $29.5[27.9,33.8]$ \\
\hline ASRv1 & 25.8 & 4.98 & $-0.19[-0.56,0.12]$ & $40.0[37.7,47.0]$ \\
\hline ASRv2 & 26.1 & 3.82 & $-0.10[-0.29,0.18]$ & $39.2[36.8,46.9]$ \\
\hline $\mathrm{C} 15$ & 27.3 & 3.99 & $-0.17[-0.17,0.11]$ & $39.2[37.2,44.9]$ \\
\hline \multicolumn{5}{|c|}{ Site B: Cape Farewell (westerly tip jets) } \\
\hline CCMPv2 & 28.0 & 3.19 & $-0.19[-0.45,0.13]$ & $37.3[35.8,42.2]$ \\
\hline ERA-I & 22.2 & 2.72 & $-0.22[-0.39,0.08]$ & $29.6[28.5,32.9]$ \\
\hline ASRv1 & 23.9 & 3.53 & $-0.26[-0.44,-0.01]$ & $32.7[31.5,35.6]$ \\
\hline ASRv2 & 25.2 & 2.87 & $-0.13[-0.34,0.14]$ & $34.5[23.9,39.1]$ \\
\hline $\mathrm{C} 15$ & 24.8 & 2.21 & $0.06[-0.20,0.44]$ & $30.5[32.2,44.4]$ \\
\hline \multicolumn{5}{|c|}{ Site C: Køge Bugt Fjord (katabatic flows) } \\
\hline CCMPv2 & 19.6 & 3.21 & $0.07[-0.15,0.43]$ & $34.2[30.4,47.3]$ \\
\hline ERA-I & 18.1 & 2.90 & $0.12[-0.12,0.54]$ & $32.9[28.6,50.0]$ \\
\hline ASRv1 & 27.3 & 6.71 & $-0.58[-0.66,-0.25]$ & $37.6[36.8,39.9]$ \\
\hline ASRv2 & 28.9 & 4.48 & $-0.12[-0.58,0.27]$ & $42.5[39.7,52.2]$ \\
\hline $\mathrm{C} 15$ & 13.0 & 2.46 & $-0.11[-0.44,0.32]$ & $20.6[19.0,26.6]$ \\
\hline \multicolumn{5}{|c|}{ Site D: South Dome (Greenland Plateau jet) } \\
\hline CCMPv2 & 21.4 & 3.62 & $-0.15[-0.31,0.08]$ & $32.3[30.4,36.7]$ \\
\hline ERA-I & 21.3 & 3.39 & $-0.14[-0.31,0.10]$ & $31.7[29.9,36.2]$ \\
\hline ASRv1 & 22.4 & 3.97 & $-0.17[-0.17,0.12]$ & $34.0[32.1,39.5]$ \\
\hline ASRv2 & 22.6 & 3.09 & $-0.15[-0.54,0.17]$ & $32.0[30.3,37.3]$ \\
\hline $\mathrm{C} 15$ & 19.2 & 3.23 & $-0.31[-0.59,-0.05]$ & $26.6[25.7,29.0]$ \\
\hline \multicolumn{5}{|c|}{ Site E: Nares Strait (low-level jet) } \\
\hline CCMPv2 & 15.1 & 2.93 & $-0.18[-0.18,0.12]$ & $23.4[22.0,27.4]$ \\
\hline ERA-I & 14.6 & 2.71 & $-0.13[-0.32,0.16]$ & $22.9[21.4,27.3]$ \\
\hline ASRv1 & 17.4 & 3.69 & $-0.31[-0.61,-0.03]$ & $25.6[24.5,28.4]$ \\
\hline ASRv2 & 23.0 & 2.54 & $-0.13[-0.33,0.03]$ & $30.9[29.4,34.9]$ \\
\hline C15 & 23.6 & 2.97 & $-0.28[-0.33,0.16]$ & $30.7[29.7,33.6]$ \\
\hline
\end{tabular}

underestimation by $\mathrm{C} 15$ is, however, not expected. A similar underestimation by $\mathrm{C} 15$ results for site $\mathrm{D}$ (Figure 6d) in the Greenland Plateau jet regime. Here, CCMPv2 falls back to ERA-I again so that their return level curves overlap. The higher horizontal resolution of ASR does not increase the estimated RLs in the jet area, which indicates that there is no added value from resolutions below $30 \mathrm{~km}$ over Greenland's ice sheet. The underestimation by $\mathrm{C} 15$ seems related to katabatic wind regimes and high orographic regions and is stronger along the coast (site C) than over the plateau (site D).

An interesting area is the Nares Strait at the exit of the Smith Sound (site E, Figure 6e). Here the POT method suggests about $23 \mathrm{~m} / \mathrm{s}$ for the $\mathrm{RL}_{10}$ based on CCMPv2 and ERA-I (Table 2). Only slightly higher values result for ASRv1, but considerably higher values of about $31 \mathrm{~m} / \mathrm{s}$ result for ASRv2 and C15.

In summary, the RLs tend to increase over ocean with increasing horizontal resolution compared with ERA-I, as found by DuVivier and Cassano (2013) and Moore et al. (2016) for the mean winds. Over land, the high-resolution models deviate and the physical parameterizations become more important. Nevertheless, higher resolved models add mesoscale features to the wind field compared with the often used ERA-I.

\section{6 | DISCUSSION}

This extreme value analysis of 10 wind speed is the first that considers a multi-decadal RCM simulation at a high resolution of $15 \mathrm{~km}$, covering the entire Arctic. We have identified increasing extreme near-surface wind speeds in the Arctic with increasing horizontal resolution of atmospheric models. A model resolution of $15 \mathrm{~km}$ or less is required to fully capture extreme wind events generated by mesoscale wind systems in key areas of the Arctic. These areas are in particular: the surrounding oceans of Greenland, that is, the Irminger and GIN Seas including Denmark Strait and Baffin Bay; Greenland's ice sheet margins; and the Barents Sea including Novaya Zemlya. Our results thus confirm the findings of previous studies (DuVivier and Cassano, 2013; Hughes and Cassano, 2015; Moore et al., 2016) but are based on more robust data and we extended the extreme wind analysis to additional wind systems in the Arctic.

The results demonstrate that the coarse resolution of ERA-I is not sufficient to capture extreme wind events in these areas. Although most of the mesoscale wind features are already captured by using a horizontal resolution of $30 \mathrm{~km}$ (ASRv1), wind extremes enhance further and their spatial structure improves at $15 \mathrm{~km}$ (ASRv2, C15). Thus, we refine the recommendation by Moore and Våge (2018), who suggested to use $<30 \mathrm{~km}$. For instance the LLJ in the very narrow Nares Strait requires $<15 \mathrm{~km}$ resolution. These strong LLJ play an important role for forming the persistent climate relevant North Water Polynya in the northern Baffin 
Bay (Samelson and Barbour, 2008). Extreme winds not only open the polynya, they also induce a considerable heat loss from the ocean and hence cause the highest amount of sea ice production in the whole Arctic (Preußer et al., 2015).

Enhanced tip jets, barrier winds or katabatic winds blowing over the ocean might lead to an enhanced heat loss in the Irminger Sea and might thus cause stronger deep convection due to enhanced buoyancy loss at the ocean surface (DuVivier et al., 2016). Further, tip jets are able to solely force the Irminger Gyre (Pickart et al., 2003) and are thus a climate relevant wind phenomena.

Extreme wind speeds enhanced over the Norwegian and Barents Sea, probably in association with better resolved polar lows and marine polar air outbreaks. The latter were recently identified to intensify in higher resolved models (Kolstad, 2017). However, our results indicate that polar lows might still be under-represented, even at $15 \mathrm{~km}$ resolution. The ASR models further simulated an enhanced Novaya Zemlya bora compared with ERA-I, which frequently causes polynyas on the west coast of the archipelago (Moore, 2013). Moore (2013) noted that ASRv1 underestimates the occurrence frequency of strong bora winds. Our results indicate that ASRv2 and C15 do not increase the bora frequency, but at least ASRv2 increases their intensities.

A possible explanation why $\mathrm{C} 15$ simulates less intense katabatic winds over Greenland is that CCLM simulates too much vertical mixing within stable boundary layers (SBL; as over Greenland; Buzzi et al., 2011), which results in a less stable SBL. A realistic simulation of the SBL structure, however, is a necessary condition to simulate katabatic winds correctly (Bromwich et al., 2001; Klein et al., 2001). An adjustment of the CCLM turbulence parameterization scheme for the SBL (see Hebbinghaus and Heinemann, 2006; Cerenzia et al., 2014) would improve the results over Greenland. Until this issue is solved, we consider ASRv2 as more realistic for katabatic wind regimes, although ASR might simulate too strong katabatic winds.

Note that the identified differences in extreme winds cannot solely be attributed to the increased horizontal resolution, because different models with different dynamics and physics were compared. Besides the physical parameterizations, also the vertical resolution is of importance. DuVivier (2017) found that the combination of high horizontal and vertical resolution captured best the structure of barrier jet structures in the Denmark Strait in May 2015. How other mesoscale wind systems and their extremes behave to changes of the vertical resolution on longer timescales remains, however, an open issue.

The estimation of RLs was found to be associated with occasionally wide confidence intervals, which are related to the limited length of the time series. We draw our main conclusions based on the 11 winter half-years 2000/2001-2011/2012, but the results only differed marginally (roughly about $\pm 10 \%$ ) from the statistics based on the whole period 1979/1980-2015/2016. This indicates that the 11 winter-half years include the whole range of wind speeds as simulated in the longer period.

We used the profile log-likelihood method to account for the asymmetry of the RL confidence intervals. Compared with the generally used delta method, this method produces wider intervals, which are asymmetrical to higher RLs. Moreover, the accuracy of the fitted GPD and hence the uncertainty of RLs depends on the chosen threshold, and the ability of the chosen extreme value distribution to represent the tail (Vinoth and Young, 2011). We could verify that changing the threshold did not affect our estimated RLs and that the GPD was well fitted for about $95 \%$ of the domain.

\section{7 | CONCLUSIONS}

In conclusion, extreme wind speeds in the Arctic, in particular around Greenland, associated with mesoscale wind phenomena increase over ocean with increasing horizontal resolution. Over land, the regional climate models show opposing results; while extreme wind speeds increase in ASR compared with ERA-Interim, they reduce or increase only marginally in C15. This seems to be conditional on the boundary layer parameterizations. Our analysis suggests that although models with a horizontal resolution of about $30 \mathrm{~km}$ are able to capture most of the spatio-temporal structure of extreme winds, a resolution of $\leq 15 \mathrm{~km}$ is required to fully capture extreme events generated by climate relevant mesoscale wind systems in the Arctic. Besides the horizontal resolution, physical parameterizations for surface fluxes and turbulence considerably affect the simulation of extreme winds. In contrast to the near-surface warming in the Arctic during the last decades, the $95 \%$ percentiles of daily maximum wind speed show no significant trends for most parts. Resolving these enhanced wind speed extremes might have a considerable effect on climate relevant air-ice-ocean interactions, such as open-ocean deep convection and the mixed layer depth, polynya dynamics, and the sea ice and freshwater balance of the Arctic.

\section{ACKNOWLEDGEMENTS}

Part of the work was funded by the Federal Ministry of Education and Research (BMBF) under grant 03G0833D. We thank the DKRZ (Hamburg) for providing computing time. The authors like to thank the CLM-Community for providing the COSMO-CLM basic model and the DKRZ for providing the computational resources. We thank Lukas Schefczyk (University of Trier) for preparing the OSI SAF data. We thank the ECMWF for providing the ERA-Interim data. The ASR data were made available by the National Center for Atmospheric Research Staff (Eds) (thanks to ChiFan Shih). Last modified 27 March 2017. "The Climate Data Guide: Arctic System Reanalysis (ASR). The CCMP 
Version-2.0 vector wind analyses are produced by Remote Sensing Systems and made available at www.remss.com, and the OSI SAF data of EUMETSAT were available from http://osisaf.met.no. Finally, we thank two anonymous reviewers for their constructive comments. The data used here will be made available at Pangaea (https://www. pangea.de).

\section{Conflict of interests}

The authors declare no potential conflict of interests.

\section{ORCID}

Oliver Gutjahr (D) https://orcid.org/0000-0002-3116-8071

\section{REFERENCES}

Arrigo, K.R. (2007) Physical control of primary production in Arctic and Antarctic polynyas. In: Smith, W.O. and Barber, D.G. (Eds.) Polynyas: Windows to the World. Amsterdam: Elsevier, pp. 223-238. https://doi.org/10.1016/ S0422-9894(06)74007-7.

Atlas, R., Hoffman, R.N., Ardizzone, J., Leidner, S.M., Jusem, J.C., Smith, D.K and Gombos, D. (2011) A cross-calibrated, multiplatform ocean surface wind velocity product for meteorological and oceanographic applications. Bulletin of the American Meteorological Society, 92, 157-174. https://doi.org/10. 1175/2010BAMS2946.1.

Barber, D., Marsden, R., Minnett, P., Ingram, G. and Fortier, L. (2001) Physical processes within the North Water (NOW) polynya. Atmosphere-Ocean, 39 163-166. https://doi.org/10.1080/07055900.2001.9649673.

Bauer, M., Schröder, D., Heinemann, G., Willmes, S. and Ebner, L. (2013) Quantifying polynya ice production in the Laptev Sea with the COSMO model Polar Research, 32, 20922. https://doi.org/10.3402/polar.v32i0.20922.

Bromwich, D.H., Cassano, J., Klein, T., Heinemann, G., Hines, K., Steffen, K. and Box, J. (2001) Mesoscale modeling of katabatic winds over Greenland with polar MM5. Monthly Weather Review, 129, 2290-2309. https://doi. org/10.1175/1520-0493(2001)129<2290:MMOKWO>2.0.CO;2.

Bromwich, D.H., Bai, L., Hines, K., Wang, Z., Liu, H., Lin, Z., Kuo, Y. and Barlage, M. (2012) Arctic System Reanalyis (ASR) Project. Boulder, CO: Research Data Archive, Computational and Information Systems Laboratory, National Center for Atmospheric Research. https://doi.org/10.5065/D6K072B5.

Bromwich, D.H., Wilson, A.B., Bai, L., Liu, Z., Barlage, M., Shih, C.F., Maldonado, S., Hines, K.M., Wang, S.H., Woollen, J., Kuo, B., Lin, H.C., Wee, T.K., Serreze, M.C. and Walsh, J.E. (2017) The Arctic System Reanalysis version 2. Bulletin of the American Meteorological Society, 99, 805-828. https://doi.org/10.1175/BAMS-D-16-0215.1.

Browning, K.A. (2004) The sting jet at the end of the tail: damaging winds associated with extratropical cyclones. Quarterly Journal of the Royal Meteorological Society, 130, 375-399. https://doi.org/10.1256/qj.02.143.

Brunner, R.D., Lynch, A.H., Pardikes, J.C., Cassano, E.N., Lestak, L.R. and Vogel, J.M. (2004) An Arctic disaster and its policy implications. Arctic, 57(4), 336-346.

Buckley, M.W. and Marshall, J. (2016) Observations, inferences, and mechanisms of the Atlantic meridional overturning circulation: a review. Reviews of Geophysics, 54, 5-63. https://doi.org/10.1002/2015RG000493.

Businger, S. (1985) The synoptic climatology of polar-low outbreaks over the Gulf of Alaska and the Bering Sea. Tellus A, 37, 419-432. https://doi.org/10. 3402/tellusa. v39i4.11762.

Buzzi, M., Rotach, M.W., Holtslag, M. and Albert, A. (2011) Evaluation of the COSMO-SC turbulence scheme in a shear-driven stable boundary layer. Meteorologische Zeitschrift, 20(3), 335-350. https://doi.org/10.1127/0941 $-2948 / 2011 / 0050$.

Cavalieri, D.J. and Martin, S. (1994) The contribution of Alaskan, Siberian, and Canadian coastal polynyas to the cold halocline layer of the Arctic Ocean. Journal of Geophysical Research, 99, 18343-18362. https://doi.org/10. 1029/94JC01169.
Cerenzia, I., Tampieri, F. and Tesini, M. (2014) Diagnosis of turbulence schema in stable atmospheric conditions and sensitivity tests. COSMO Newsletter, $14,28-36$

Choulakian, V. and Stephens, M.A. (2001) Goodness-of-fit tests for the generalized Pareto distribution. Technometrics, 43(4), 478-484.

Clark, P.A. and Gray, S.L. (2018) Sting jets in extratropical cyclones: a review. Quaterly Journal of the Royal Meteorological Society (accepted). https://doi. org/10.1002/qj.3267.

Coles, S. (2001) An Introduction to Statistical Modeling of Extreme Values, 1st edition. Berlin: Springer, 224 pp. isbn: 1852334592

Condron, A. and Renfrew, I.A. (2013) The impact of polar mesoscale storms on northeast Atlantic Ocean circulation. Nature Geoscience, 6(1), 34-37. https://doi.org/10.1038/ ngeo1661.

Dee, D.P., Uppala, S.M., Simmons, A.J., Berrisford, P., Poli, P., Kobayashi, S., Andrae, U., Balmaseda, M.A., Balsamo, G., Bauer, P., Bechtold, P., Beljaars, A.C.M., van de Berg, L., Bidlot, J., Bormann, N., Delsol, C., Dragani, R., Fuentes, M., Geer, A.J., Haimberger, L., Healy, S.B., Hersbach, H., Hólm, E.V., Isaksen, L., Kåberg, P., Köhler, M., Matricardi, M., McNally, A.P., Monge-Sanz, B.M., Morcrette, J.J., Park, B. K., Peubey, C., de Rosnay, P., Tavolato, C., Thépaut, J.N. and Vitart, F. (2011) The ERA-Interim reanalysis: configuration and performance of the data assimilation system. Quarterly Journal of the Royal Meteorological Society, 137(656), 553-597. https://doi.org/10.1002/qj.828.

Doyle, J.D. and Shapiro, M.A. (1999) Flow response to large-scale topography: the Greenland tip jet. Tellus A, 51, 728-748.

DuVivier, A.K. (2017) A case study of observed and modeled barrier flow in the Denmark Strait in May 2015. Monthly Weather Review, 145, 2385-2404. https://doi.org/10.1175/MWR-D-16-0386.1.

DuVivier, A.K. and Cassano, J.J. (2013) Evaluation of WRF model resolution on simulated mesoscale winds and surface fluxes near Greenland. Monthly Weather Review, 141(3), 941-963. https://doi.org/10.1175/MWR-D-1200091.1.

DuVivier, A.K. and Cassano, J.J. (2015) Exploration of turbulent heat fluxes and wind stress curl in WRF and ERA-Interim during wintertime mesoscale wind events around southeastern Greenland. Journal of Geophysical Research: Atmospheres, 120(9), 3593-3609. https://doi.org/10.1002/2014JD022991.

DuVivier, A.K. and Cassano, J.J. (2016) Comparison of wintertime mesoscale winds over the ocean around southeastern Greenland in WRF and ERA-Interim. Climate Dynamics, 46, 2197-2211. https://doi.org/10.1007/ s00382-015-2697-8.

DuVivier, A.K., Cassano, J., Craig, A., Hamman, J., Maslowski, W., Nijssen, B., Osinski, R. and Roberts, A. (2016) Winter atmospheric buoyancy forcing and oceanic response during strong wind events around southeastern Greenland in the Regional Arctic System Model (RASM) for 1990-2010. Journal of Climate, 29, 975-994. https://doi.org/10.1175/JCLI-D-15-0592.1.

Ebner, L., Schröder, D. and Heinemann, G. (2011) Impact of Laptev Sea flaw polynyas on the atmospheric boundary layer and ice production using idealized mesoscale simulations. Polar Research, 30, 7210. https://doi.org/10. 3402/polar.v30i0.7210.

EUMETSAT Ocean and Sea Ice Satellite Application. (2015) Global sea ice concentration reprocessing dataset 1978-2015 (v1.2, 2015). Norwegian and Danish Meteorological Institutes. Available at: http://osisaf.met.no. [Accessed 7th March 2017].

Gautier, D.L., Bird, K.J., Charpentier, R.R., Grantz, A., Houseknecht, D.W., Klett, T.R., Moore, T.E., Pitman, J.K., Schenk, C.J., Schuenemeyer, J.H., Sørensen, K., Tennyson, M.E., Valin, Z.C. and Wandrey, C.J. (2009) Assessment of undiscovered oil and gas in the Arctic. Science, 324(5931), 1175-1179. https://doi.org/10.1126/science.1169467.

Ghil, M., Yiou, P., Hallegatte, S., Malamud, B.D., Naveau, P., Soloviev, A., Friederichs, P., Keilis-Borok, V., Kondrashov, D., Kossobokov, V., Mestre, O., Nicolis, C., Rust, H.W., Shebalin, P., Vrac, M., Witt, A. and Zaliapin, I. (2011) Extreme events: dynamics, statistics and prediction. Nonlinear Processes in Geophysics, 18(3), 295-350. https://doi.org/10.5194/ npg-18-295-2011.

Gutjahr, O., Heinemann, G., Preußer, A., Willmes, S. and Drüe, C. (2016a) Quantification of ice production in Laptev Sea polynyas and its sensitivity to thin-ice parameterizations in a regional climate model. Cryosphere, 10, 2999-3019. https://doi.org/10.5194/tc-10-2999-2016.

Gutjahr, O., Schefczyk, L., Reiter, P. and Heinemann, G. (2016b) Impact of the horizontal resolution on the simulation of extremes in COSMO-CLM. 
Meteorologische Zeitschrift, 25(5), 543-562. https://doi.org/10.1127/ metz/2016/0638.

Haine, T.W.N., Zhang, S., Moore, G.W.K. and Renfrew, I.A. (2009) On the impact of high-resolution, high-frequency meteorological forcing on Denmark Strait ocean circulation. Quarterly Journal of the Royal Meteorological Society, 135(645), 2067-2085. https://doi.org/10.1002/qj.505.

Hakkinen, S., Proshutinsky, A. and Ashik, I. (2008) Sea ice drift in the Arctic since the 1950s. Geophysical Research Letters, 35, L19704. https://doi. org/10.1029/2008GL034791.

Hanesiak, J.M., Brimelow, J.C., Zadra, A., Goodson, R. and Liu, G. (2013) Structure and predictive skill of strong northeasterly wind events using a limited area numerical weather prediction model at Iqaluit, Canada. Tellus A, 65, 19, 782. https://doi.org/10.3402/tellusa.v65i0.19782.

Harden, B.E. and Renfrew, I.A. (2012) On the spatial distribution of high winds off southeast Greenland. Geophysical Research Letters, 39, L14806. https:// doi.org/10.1029/2012GL052245.

Harper, J. (1978) Coastal erosion rates along the Chuckchi Sea coast near Barrow, Alaska. Arctic, 31(4), 428-433.

Hastings, D., Dunbar, P.K., Elphingstone, G.M., Bootz, M., Murakami, H., Maruyama, H., Masaharu, H., Holland, P., Payne, J., Bryant, N.A., Logan, T.L., Muller, J.P., Schreier, G. and MacDonald, J.S. (1999) The Global Land One-kilometer Base Elevation (GLOBE) Digital Elevation Model, Version 1.0.. Boulder, CO: National Geophysical Data Center, National Oceanic and Atmospheric Administration. Available at: http:// www.ngdc.noaa.gov/mgg/topo/globe.html. [Accessed 26th February 2017].

Hebbinghaus, H. and Heinemann, G. (2006) LM simulations of the Greenland boundary layer, comparison with local measurements and SNOWPACK simulations of drifting snow. Cold Regions Science Technology, 46, 36-51. https://doi.org/10.1016/j.coldregions. 2006.05.003.

Heinemann, G. (2003) Forcing and feedback mechanisms between the katabatic wind and sea ice in the coastal areas of polar ice sheets. Global Atmosphere and Ocean System, 9, 169-201. https://doi.org/10.1080/1023673042000198130.

Heinemann, G. and Claud, C. (1997) Report of a workshop on "theoretical and observational studies of polar lows" of the European Geophysical Society Polar Lows Working Group. Bulletin of the American Meteorological Society, 78, 2643-2658. https://doi.org/10.1175/1520-0477-78.11.2643.

Heinemann, G. and Klein, T. (2002) Modelling and observations of the katabatic flow dynamics over Greenland. Tellus A, 54, 542-554. https://doi.org/10. 1034/j.1600-0870.2002.201401.x.

Heise, E., Ritter, B. and Schrodin, R. (2006) Operational implementation of the multilayer soil model, consortium for small-scale modelling (COSMO). Offenbach: Deutscher Wetterdienst. Technical report number: 9.

Hines, K.M., Bromwich, D.H., Bai, L., Bitz, C.M., Powers, J. and Manning, K. (2015) Sea ice enhancements to polar WRF. Monthly Weather Review, 143, 2363-2385. https://doi.org/10.1175/MWR-D-14-00344.1.

Holmes, J. and Moriarty, W. (1999) Application of the generalized Pareto distribution to extreme value analysis in wind engineering. Journal of Wind Engineering and Industrial Aerodynamics, 83, 1-10. https://doi.org/10.1016/ s0167-6105(99)00056-2.

Hughes, M. and Cassano, J.J. (2015) The climatological distribution of extreme Arctic winds and implications for ocean and sea ice processes. Journal of Geophysical Research: Atmospheres, 120(15), 7358-7377. https://doi. org/10.1002/2015JD023189.

Janout, M., Hölemann, J., Timokhov, L., Gutjahr, O. and Heinemann, G. (2017) Circulation in the northwest Laptev Sea in the eastern Arctic Ocean: crossroads between Siberian River water, Atlantic water and polynya-formed dense water. Journal of Geophysical Research: Oceans, 122, 7647-7662. https://doi.org/10.1002/2017JC013159.

de Jong, M.F. and de Steur, L. (2016) Strong winter cooling over the Irminger Sea in winter 2014-2015, exceptional deep convection, and the emergence of anomalously low SST. Geophysical Research Letters, 43, 7106-7113. https://doi.org/10.1002/2016GL069596.

Jung, T., Serrar, S. and Wang, Q. (2014) The oceanic response to mesoscale atmospheric forcing. Geophysical Research Letters, 41, 1255-1260. https:// doi.org/10.1002/2013g1059040.

Klein, T. and Heinemann, G. (2002) Interaction of katabatic winds and mesocyclones near the eastern coast of Greenland. Meteorological Applications, 9, 407-422. https://doi.org/10.1017/s1350482702004036.

Klein, T., Heinemann, G., Bromwich, D.H., Cassano, J. and Hines, K. (2001) Mesoscale modeling of katabatic winds over Greenland and comparisons with AWS and aircraft data. Meteorology and Atmospheric Physics, 78, 115-132. https://doi.org/10.1007/ s007030170010.

Knote, C., Heinemann, G. and Rockel, B. (2010) Changes in weather extremes: assessment of return values using high resolution climate simulations at convection-resolving scale. Meteorologische Zeitschrift, 19, 11-23. https:// doi.org/10.1127/0941-2948/2010/0424.

Kohnemann, S.H.E., Heinemann, G., Bromwich, D.H. and Gutjahr, O. (2017) Extreme warming in the Kara Sea and Barents Sea during the winter period 2002-2016. Journal of Climate, 30, 8913-8927. https://doi.org/10.1175/ JCLI-D-16-0693.1.

Kolstad, E.W. (2008) A QuikSCAT climatology of ocean surface winds in the Nordic Seas: identification of features and comparison with the NCEP/NCAR reanalysis. Journal of Geophysical Research, 113, D11106. https://doi. org/10.1029/2007JD008918.

Kolstad, E.W. (2015) Extreme small-scale wind episodes over the Barents Sea: when, where and why? Climate Dynamics, 45(7-8), 2137-2150. https://doi. org/10.1007/ s00382-014-2462-4.

Kolstad, E.W. (2017) Higher ocean wind speeds during marine cold air outbreaks. Quarterly Journal of the Royal Meteorological Society, 143, 2084-2092. https://doi.org/10.1002/qj.3068.

Kolstad, E.W., Bracegirdle, T.J. and Seierstad, I.A. (2009) Marine cold-air outbreaks in the North Atlantic: temporal distribution and associations with large-scale atmospheric circulation. Climate Dynamics, 33, 187-197. https:// doi.org/10.1007/ s00382-008-0431-5.

Køltzow, M. (2007) The effect of a new snow and sea ice albedo scheme on regional climate model simulations. Journal of Geophysical Research, 112, D07110. https://doi.org/10.1029/2006JD007693.

Kwok, R., Spreen, G. and Pang, S. (2013) Arctic Sea ice circulation and drift speed: decadel trends and ocean currents. Journal of Geophysical Research: Oceans, 118, 2408-2425. https://doi.org/10.1002/jgrc.20191.

Leadbetter, M.R., Weissmann, I., de Haan, L. and Rootzén, H. (1989) On clustering of high values in statistically stationary series. Chapel Hill: Center for Stochastic Processes, University of North Carolina. Technical report number: 253.

Louis, J.F. (1979) A parametric model of vertical eddy fluxes in the atmosphere. Boundary-Layer Meteorology, 17(2), 187-202. https://doi.org/10.1007/ BF00117978.

Mann, H.B. (1945) Nonparametric tests against trend. Econometrica, 13, 245-259.

Martin, R. and Moore, G.W.K. (2007) Air-sea interaction associated with a Greenland reverse tip jet. Geophysical Research Letters, 34(24), L24802. https://doi.org/10.1029/2007GL031093.

Mellor, G.L. and Yamada, T. (1974) A hierarchy of turbulence closure models for planetary boundary layers. Journal of the Atmospheric Sciences, 31(7), 1791-1806. https://doi.org/10.1175/1520-0469(1974)031<1791:AHOTCM>2.0. $\mathrm{CO} ; 2$.

Moore, G.W.K. (2003) Gale force winds over the Irminger Sea to the east of Cape Farewell, Greenland. Geophysical Research Letters, 30(17), 1894. https://doi.org/10.1029/2003GL018012.

Moore, G.W.K. (2013) The Novaya Zemlya bora and its impact on Barents Sea air-sea interaction. Geophysical Research Letters, 40(13), 3462-3467. https://doi.org/10.1002/grl. 50641.

Moore, G.W.K. (2014) Mesoscale structure of Cape Farewell tip jets. Journal of Climate, 27(23), 8956-8965. https://doi.org/10.1175/JCLI-D-14-00299.1.

Moore, G.W.K. (2016) The March 1972 northwest Greenland windstorm: evidence of downslope winds associated with a trapped lee wave. Quarterly Journal of the Royal Meteorological Society, 142, 1428-1438. https://doi. org/10.1002/qj.2744.

Moore, G.W.K. and Pickart, R. (2012) Northern Bering Sea tip jet. Geophysical Research Letters, 39, L08807. https://doi.org/10.1029/2012GL051537.

Moore, G.W.K. and Renfrew, I.A. (2005) Tip jets and barrier winds: a QuikSCAT climatology of high wind speed events around Greenland. Journal of Climate, 18(18), 3713-3725. https://doi.org/10.1175/JCLI3455.1.

Moore, G.W.K. and Våge, K. (2018) Impact of model resolution on the representation on the air-sea interaction associated with the North Water Polynya. Quarterly Journal of the Royal Meteorological Society (accepted). https:// doi.org/10.1002/qj.3295.

Moore, G.W.K., Pickart, R.S. and Renfrew, I.A. (2008) Buoy observations from the windiest location in the world ocean, Cape Farewell, Greenland. Geophysical Research Letters, 35, L18802. https://doi.org/10.1029/2008GL034845.

Moore, G., Renfrew, I. and Cassano, J. (2013) Greenland plateau jets. Tellus A, 69, 17468. https://doi.org/10.3402/tellusa.v65i0.17468. 
Moore, G.W.K., Renfrew, I.A., Harden, B.E. and Mernild, S.H. (2015) The impact of resolution on the representation of southeast Greenland barrier winds and katabatic flows. Geophysical Research Letters, 42(8), 3011-3018. https://doi.org/10.1002/2015GL063550.

Moore, G.W.K., Bromwich, D.H., Wilson, A.B., Renfrew, I. and Bai, L. (2016) Arctic system reanalysis improvements in topographically-forced winds near Greenland. Quarterly Journal of the Royal Meteorological Society, 142, 2033-2045. https://doi.org/10.1002/qj.2798.

Oltmanns, M., Straneo, F., Moore, G.W.K. and Mernild, S.H. (2014) Strong downslope wind events in Ammassalik, southeast Greenland. Journal of Climate, 27, 977-993. https://doi.org/10.1175/jcli-d-13-00067.1.

Outten, S.D., Renfrew, I.A. and Petersen, G.N. (2009) An easterly tip jet off Cape Farewell, Greenland. II: simulations and dynamics. Quarterly Journal of the Royal Meteorological Society, 135(645), 1934-1949. https://doi. org/10.1002/qj.531.

Papritz, L. (2017) Synoptic environments and characteristics of cold air outbreaks in the Irminger Sea. International Journal of Climatology, 37A, 193-207. https://doi.org/10.1002/joc.4991.

Papritz, L. and Spengler, T. (2016) A Lagrangian climatology of winterimte cold air outbreaks in the Irminger and Nordic Seas and their role in shaping airsea heat fluxes. Journal of Climate, 30, 2717-2737. https://doi.org/10.1175/ JCLI-D-16-0605.1.

Pickart, R.S., Spall, M.A., Ribergaard, M.H., Moore, G.W.K. and Milliff, R.F. (2003) Deep convection in the Irminger Sea forced by the Greenland tip jet. Nature, 424(6945), 152-156. https://doi.org/10.1038/nature01729.

Polar Meterology Group/Byrd Polar Research Center/The Ohio State University. (2017) Arctic System Reanalysis Version 2. Boulder, CO: Research Data Archive, Computational and Information Systems Laboratory, National Center for Atmospheric Research. Available at: http://rda.ucar.edu/datasets/ds631.1 [Accessed 12th March 2017].

Preußer, A., Heinemann, G., Willmes, S. and Paul, S. (2015) Multi-decadal variability of polynya characteristics and ice production in the north water polynya by means of passive microwave and thermal infrared satellite imagery. Remote Sensing, 7(12), 15844-15867. https://doi.org/10.3390/rs71215807.

Rasmussen, L. (1989) Greenland winds and satellite imagery. Vejret-Danish Meteorological Society, 32-37.

Reeve, M.A. and Kolstad, E.W. (2011) The Spitsbergen South Cape tip jet. Quarterly Journal of the Royal Meteorological Society, 137(660), 1739-1748. https://doi.org/10.1002/qj.876.

Ricciardulli, L. and NCAR Staff. (2016) The climate data guide: CCMP: cross-calibrated mulit-platform wind vector analysis. Available at: https:// climatedataguide.ucar.edu/climate-data/ccmp-cross-calibrated-multi-platformwind-vector-analysis. [Accessed 10th March 2017].

Samelson, R.M. and Barbour, P.L. (2008) Low-level jets, orographic effecs, and extreme events in Nares Strait: a model-based mesoscale climatology. Monthly Weather Review, 136, 4746-4759. https://doi.org/10.1175/2007MW R2326.1.

Sampe, T. and Xie, S.P. (2007) Mapping high sea winds from space: a global climatology. Bulletin of the American Meteorological Society, 88(12), 1965-1978. https://doi.org/10.1175/ BAMS-88-12-1965.

Schröder, D., Heinemann, G. and Willmes, S. (2011) The impact of a thermodynamic sea-ice module in the COSMO numerical weather prediction model on simulations for the Laptev Sea, Siberian Arctic. Polar Research, 30(1), 6334. https://doi.org/10.3402/polar.v30i0.6334.

Schultz, D.M. and Browning, K.A. (2017) What is a sting jet? Weather, 72(3), 63-66. https://doi.org/10.1002/wea.2795.

Schultz, D.M. and Sienkiewicz, J.M. (2013) Using frontogenesis to identify possible sting jets in extratropical cyclones. Weather and Forecasting, 28, 603-613. https://doi.org/10.1175/ WAF-D-12-00126.1.

Serreze, M.C. and Barry, G. (2011) Processes and impacts of Arctic amplification: a research synthesis. Global and Planetary Change, 77, 85-96. https:// doi.org/10.1016/j.gloplacha.2011.03.004.

Shapiro, M. and Keyser, D. (1990) Fronts, jet streams and the tropopause. In: Newton, C.O. and Holopainen, E.O. (Eds.) Extratropical Cyclones: The Erik Palmén Memorial Volume. Boston, MA: American Meteorological Society, pp. 167-189.

Simmonds, I. and Keay, K. (2009) Extraordinary September Arctic sea ice reductions and their relationships with storm behaviour over 1979-2008. Geophysical Research Letters, 36, L19715. https://doi.org/10.1029/2009GL039810.

Simmonds, I. and Rudeva, I. (2012) The great Arctic cyclone of August 2012. Geophysical Research Letters, 39, L23709. https://doi.org/10.1029/2012GL054259.
Skamarock, W.C. (2004) Evaluating mesoscale NWP models using kinetic energy spectra. Monthly Weather Review, 132(12), 3019-3032. https://doi. org/10.1175/MWR2830.1.

Spall, M.A. and Pickart, R.S. (2003) Wind-driven recirculations and exchange in the Labrador and Irminger Seas. Journal of Physical Oceanography, 33(8), 1829-1845. https://doi.org/10.1175/2384.1

Spall, M.A. and Price, J.F. (1998) Mesoscale variability in Denmark Strait: the PV outflow hypothesis. Journal of Physical Oceanography, 28, 1598-1623.

Spengler, T., Claud, C. and Heinemann, G. (2017) Summary for the 13th polar low workshop. Bulletin of the American Meteorological Society, 98, ES139-ES142. https://doi.org/10.1175/ BAMS-D-16-0207.1.

Spreen, G., Kwok, R. and Menemenlis, D. (2011) Trends in Arctic sea ice drift and role of wind forcing: 1992-2009. Geophysical Research Letters, 38, L19501. https://doi.org/10.1029/2011GL048970.

Sproson, D.A.J., Renfrew, I.A. and Heywood, K.J. (2008) Atmospheric conditions associated with oceanic convection in the south-east Labrador Sea. Geophysical Research Letters, 35, L06601. https://doi.org/10.1029/2007GL032971.

Sproson, D.A.J., Renfrew, I.A. and Heywood, K.J. (2010) A parameterization of Greenland's tip jets suitable for ocean or coupled climate models. Journal of Geophysical Research: Oceans, 115(C8), C08022. https://doi.org/10.1029/ 2009JC006002.

Stegall, S.T. and Zhang, J. (2012) Wind field climatology, changes, and extremes in the Chukchi-Beaufort Seas and Alaska North Slope during 1979-2009. Journal of Climate, 25, 8075-8089. https://doi.org/10.1175/JCLI-D-11-00532.1.

Stirling, I. (1997) The importance of polynyas, ice edges, and leads to marine mammals and birds. Journal of Marine Systems, 10, 9129-9136.

Stroeve, J.C., Kattsov, V., Barrett, A., Serreze, M., Pavlova, T., Holland, M. and Meier, W.N. (2012) Trends in Arctic sea ice extent from CMIP5, CMIP3 and observations. Geophysical Research Letters, 39(16), L16502. https://doi. org/10.1029/2012GL052676.

Tuononen, M., Sinclair, V.A. and Vihma, T. (2015) A climatology of low-level jets in the mid-latitudes and polar regions of the Northern Hemisphere. Atmospheric Science Letters, 16, 492-499. https://doi.org/10.1002/asl.587.

Våge, K. (2009) Multi-event analysis of the westerly Greenland tip jet based upon 45 winters in ERA-40. Quarterly Journal of the Royal Meteorological Society, 135, 1999-2011. https://doi.org/10.1002/qj.488.

Våge, K., Pickart, R.S., Moore, G.W.K. and Ribergaard, M.H. (2008) Winter mixed layer development in the central Irminger Sea: the effect of strong, intermittent wind events. Journal of Physical Oceanography, 38(3), 541-565. https://doi.org/10.1175/2007JPO3678. 1.

Vinoth, J. and Young, I.R. (2011) Global estimates of extreme wind speed and wave height. Journal of Climate, 24(6), 1647-1665. https://doi.org/10. 1175/2010JCLI3680.1.

Wentz, F., Hilburn, K. and Smith, D. (2012) Remote sensing systems DMSP SSM/I daily environmental suite on 0.25 deg grid, version 7. Santa Rosa, CA: Remote Sensing Systems. Available at: www.remss.com/missions/ssmi.

Wentz, F., Meissner, T., Gentemann, C., Hilburn, K. and Scott, J. (2014) Remote sensing systems GCOM-W1 AMSR2 daily environmental suite on 0.25 deg grid, version 7.2. Santa Rosa, CA: Remote Sensing Systems. Available at: www.remss.com/missions/amsre.

Wentz, F., Scott, J., Hoffman, R., Leidner, M., Atlas, R. and Ardizzone, J. (2015) Remote sensing systems cross-calibrated multi-platform (CCMP) 6-hourly ocean vector wind analysis product on $0.25 \mathrm{deg}$ grid, version 2.0. Santa Rosa, CA: Remote Sensing Systems.

Zentek, R., Heinemann, G. and Sachs, E. (2016) Climatology of wind, kinetic energy and temperature spectra using a high-resolution climage model for mid-Europe. Journal of Climate, 29, 963-974. https://doi.org/10.1175/ JCLI-D-15-0540.1.

Zhang, J. and Rothrock, D.A. (2003) Modeling global sea ice with a thickness and enthalpy distribution model in generalized curvilinear coordinates. Monthly Weather Review, 131(5), 845-861. https://doi.org/10.1175/1520-04 93(2003)131<0845:MGSIWA>2.0.CO;2.

How to cite this article: Gutjahr O, Heinemann G. A model-based comparison of extreme winds in the Arctic and around Greenland. Int J Climatol. 2018;38: 5272-5292. https://doi.org/10.1002/joc.5729 


\section{APPENDIX A: CALCULATION OF RETURN LEVELS WITH THE POT METHOD}

\section{A1. DATA PREPARATION}

We used daily maximum values of $10 \mathrm{~m}$ wind speed $\left(U_{10 x}\right)$ during wintertime (November-April) for the POT method. $U_{10 x}$ was aggregated from the subdaily data (Table 1 ). $U_{10 x}$ might thus underestimate the actual maximum wind speed values. The fields from ASR, ERA-I, and CCMPv2 were interpolated bilinearly onto the $\mathrm{C} 15$ grid.

All time series have been detrended and declustered prior to the POT method. We used the "run-length" declustering after Leadbetter et al. (1989). This approach defines a window or cluster of length $r_{l}$ (decorrelation time) enclosing an exceedance in which only the largest value is kept for the subsequent analysis. We estimated $r_{l}$ as the winter-average of the largest time-lag of the auto-correlation function that is significant on the 95\% level following Knote et al. (2010) and Gutjahr et al. (2016b). Figure A2a-c shows the resulting $r_{l}$ for both ASR models and C15. ASRv2 and C15 show similar $r_{l}$ values of about 1-3 days for most of the Arctic, whereas in ASRv1 $r_{l}$ reaches 10 days in the Labrador Sea and Bering Strait, and longer $r_{l}$ result along the marginal ice zone and in the Kara Sea. Why ASRv1 simulates stronger auto-correlated wind speeds in these areas cannot be explained by our statistics.

\section{A.2. GPD FITTING AND RETURN LEVEL CALCULATION}

To assess extreme wind speeds, the POT method (Holmes and Moriarty, 1999; Coles, 2001) was applied as described in more detail by Gutjahr et al. (2016b). In the POT method extremes are defined as exceedances above a certain threshold $u$. The cumulative distribution function for the GPD $\left(F_{u}\right)$ is then defined for threshold exceedances $x=(X-u \mid X>u)$ of a vector $X$ as

$$
F_{u}(x)=\left\{\begin{array}{ll}
1-\left(1+\frac{\xi x}{\sigma}\right)^{-1 / \xi} & \text { if } \xi \neq 0 \\
1-\exp \left(-\frac{x}{\sigma}\right) & \text { if } \xi=0
\end{array},\right.
$$

with $u$ the threshold, $\sigma$ the scale parameter, and $\xi$ the shape parameter (a)

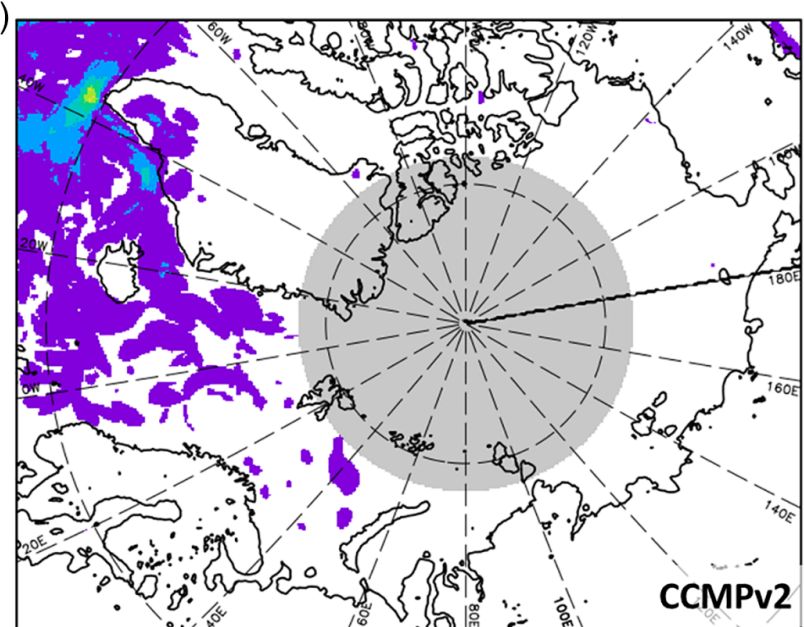

(c)

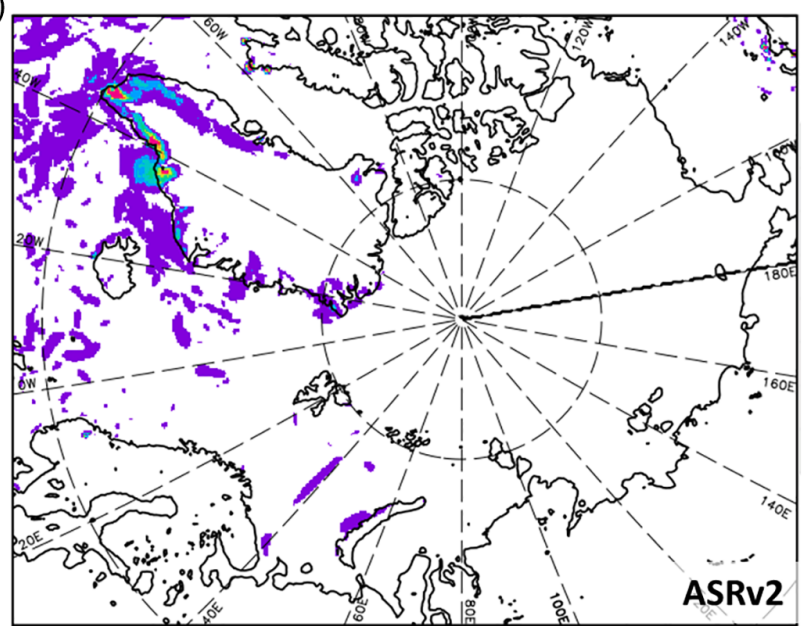

(b)

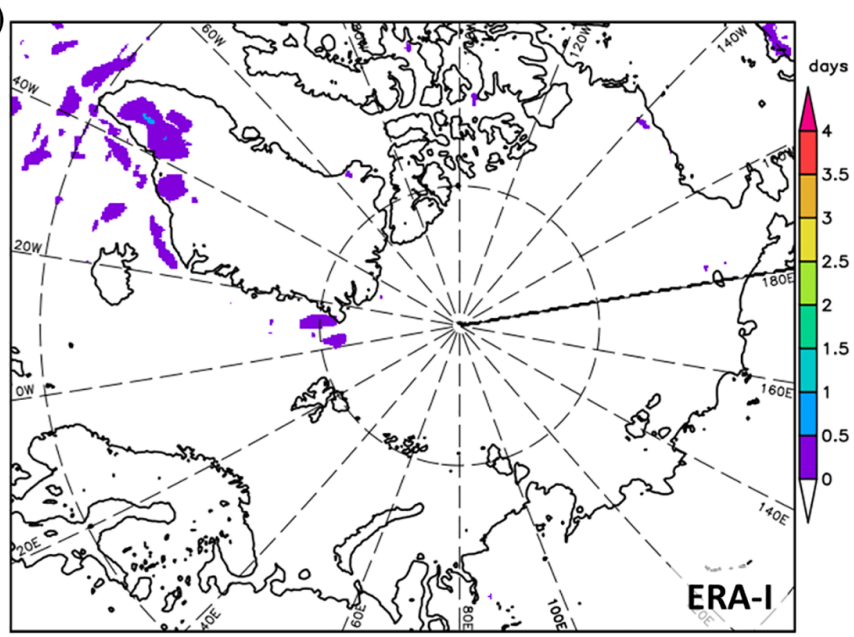

(d)

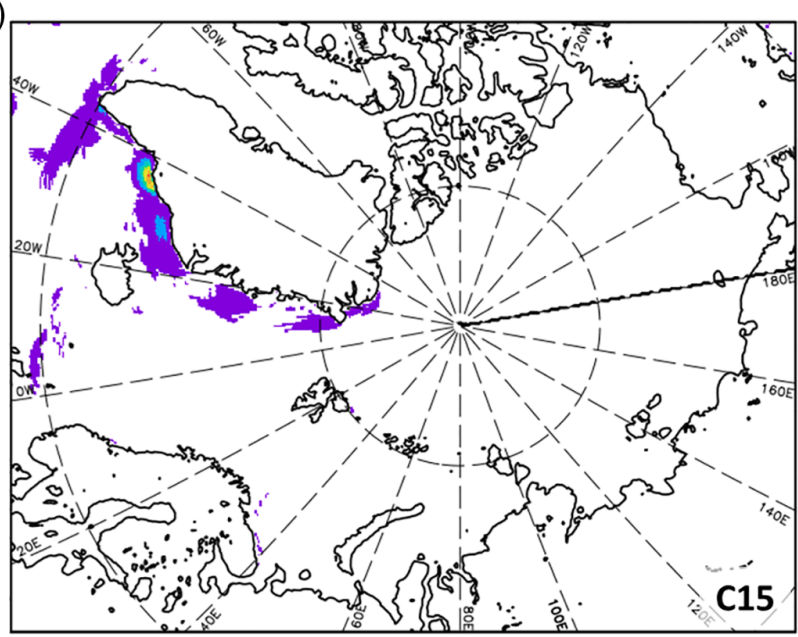

FIGURE A1 Average number of hurricane days $\left(S_{h}:=\right.$ wind speeds $>32.5 \mathrm{~m} / \mathrm{s}$ ) per winter half-year (November-April) 2000/2001-2011/2012 from (a) CCMPv2, (b) ERA-I, (c) ASRv2, and (d) C15 [Colour figure can be viewed at wileyonlinelibrary.com] 
(a)

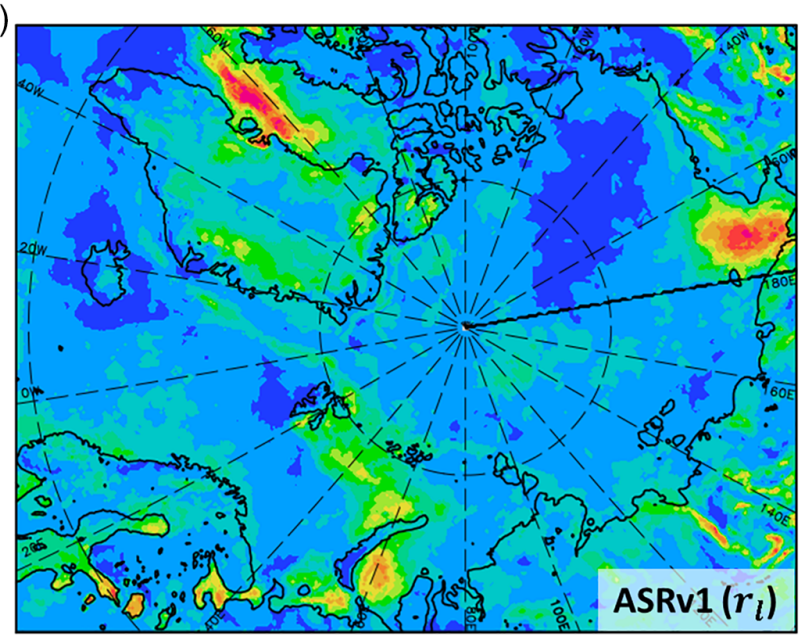

(c)

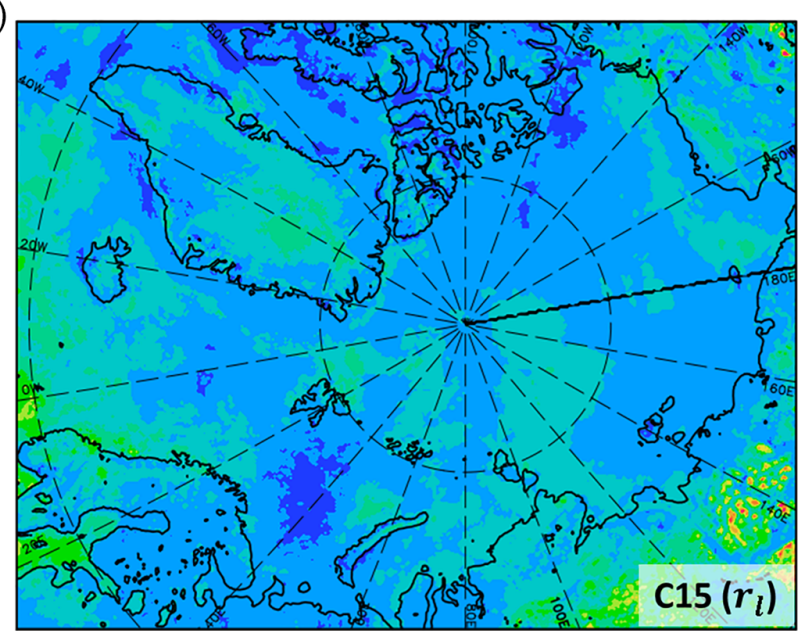

(b)

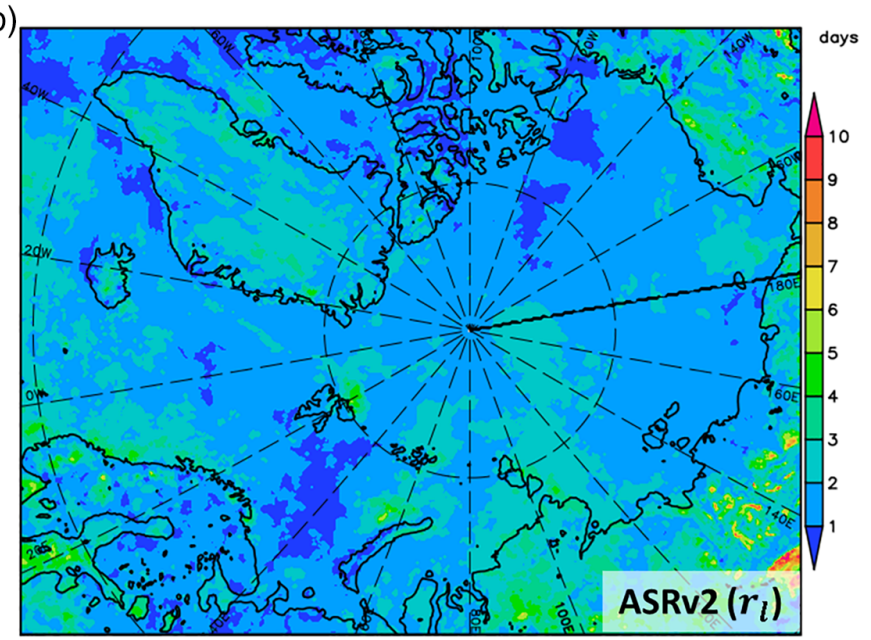

(e)

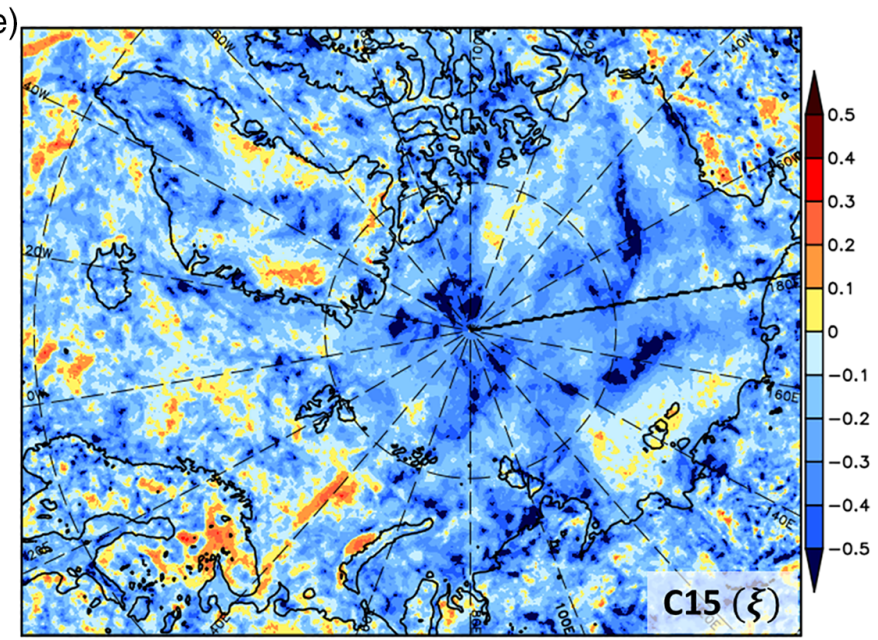

FIGURE A2 Estimated "run length" $r_{l}$ that is used for decorrelating the extreme wind events for (a) ASRv1, (b) ASRv2, and (c) C15 calculated from the winter half-years 2000/2001-2011/2012. In (d) the shape parameters ( $\xi$ ) of the fitted GPD for C15 are shown [Colour figure can be viewed at wileyonlinelibrary.com]

The POT method was applied to every grid box and RLs were calculated by assuming spatial independence. After fitting the GPD, return levels can be estimated for a specific return period $m$ by rearranging Equation A1 (see Coles, 2001 for details),

$$
\mathrm{RL}_{m}=\left\{\begin{array}{ll}
u+\frac{\sigma}{\xi}\left[\left(m n_{y} \zeta_{u}\right)^{\xi}-1\right] & \text { if } \xi \neq 0 \\
u+\sigma \log \left(m n_{y} \zeta_{u}\right) & \text { if } \xi=0
\end{array},\right.
$$

with $u, \sigma, \xi$ the threshold, scale and shape parameter of the GPD, $m$ the return period in years, $n_{y}$ the number of observations per year and $\zeta_{u}$ the exceedance probability. The estimated shape parameters $\xi$ for $\mathrm{C} 15$ (2000/2001-2011/2012, November-April) are shown in Figure A2d. For large parts of the Arctic $\xi$ is negative, which means that a maximum return level is reached asymptotically. The positive values seem not to obey a specific pattern, although they sometimes coincide with areas of mesoscale wind systems, for example, around Cape Farewell or at the west coast of Novaya Zemlya. The spatial distribution of $\xi$ estimated from the other models is similar to $\mathrm{C} 15$ (not shown).

Confidence intervals and sampling uncertainties of the GPD parameters and the RLs were calculated based on the profile log-likelihood method (PLL). The profile loglikelihood confidence intervals are generally asymmetric and account for higher uncertainty of large values of the process (Coles, 2001). Coles (2001) recommends to use PLL instead of the delta method whenever a more precise measure of uncertainty is required. 
(a) Mann-Kendall trend test on ERA-I 95p (2000-2012)

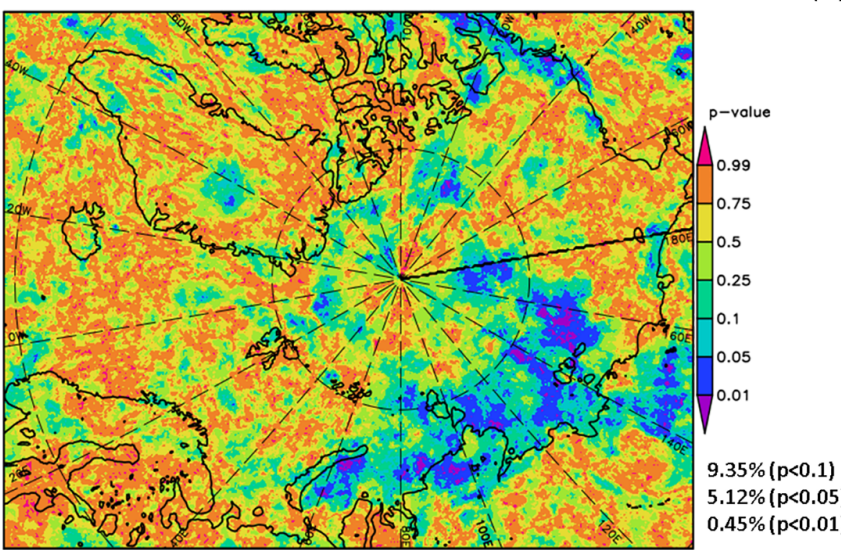

(b) Mann-Kendall trend test on C15 95p (2000-2012)

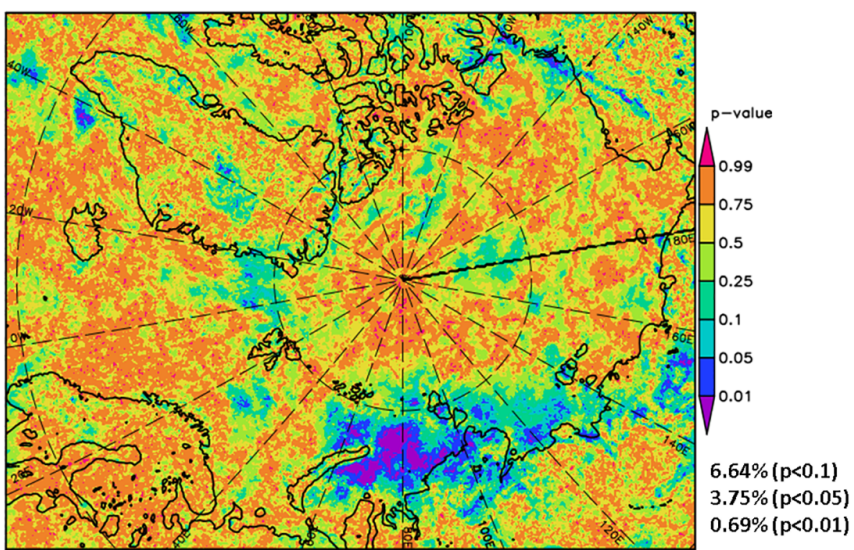

(c) Mann-Kendall trend test on ERA-I 95p (1979-2016)

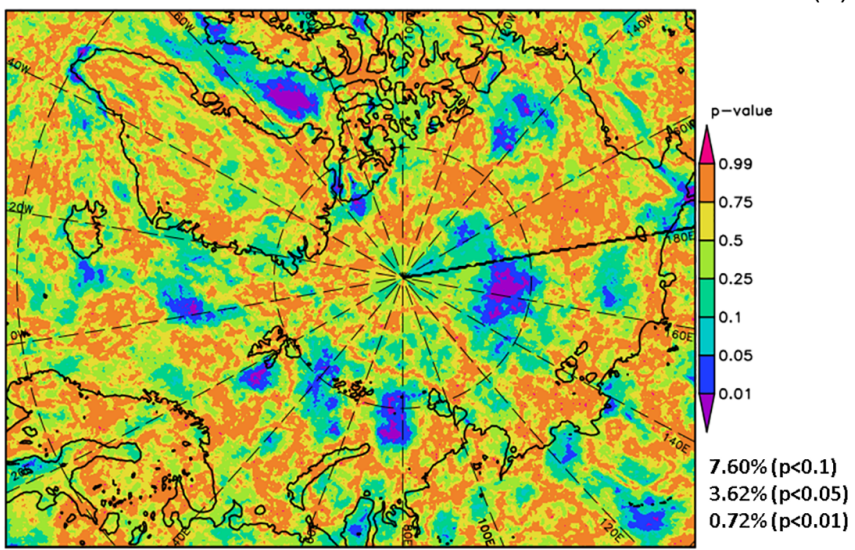

(d) Mann-Kendall trend test on C15 95p (1979-2016)

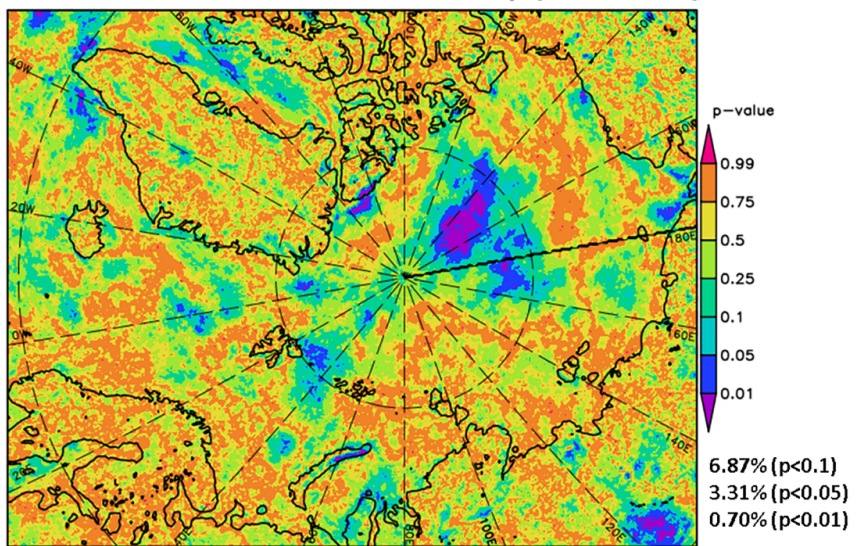

Anderson-Darling test on C15 GPD (95p, 2000-2012)

(f) bootstrapped, $n=1000$

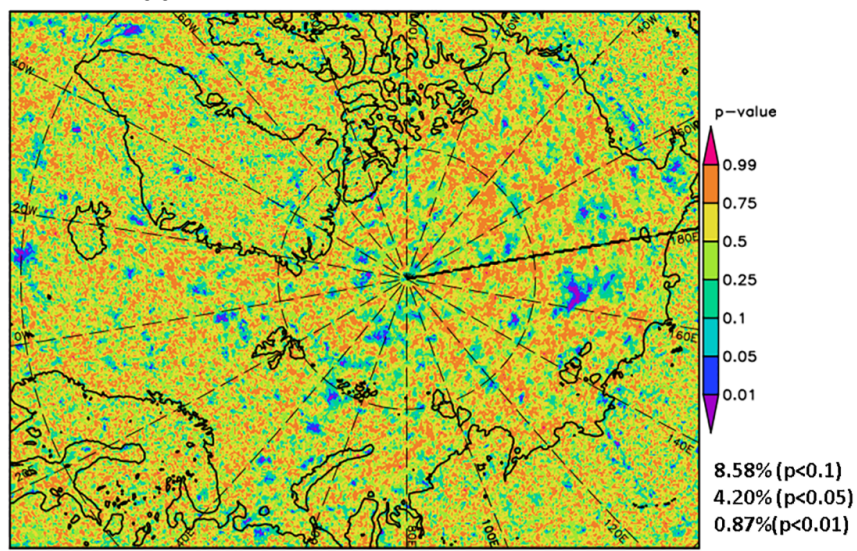

FIGURE A3 Resulting $p$-values of Mann-Kendall trend tests of the 95\% percentiles of daily maximum $10 \mathrm{~m}$ wind speeds for (a) ERA-I and (b) C15 based on the winter half-years (November-April) 2000/2001-2011/2012, and based on the winter half-years (November-April) 1979/1980-2015/2016 for (c) ERAI and (d) C15. In (e) the difference of $\mathrm{RL}_{10}$ based on the local 95\% percentiles of $\mathrm{C} 15$ minus $\mathrm{RL}_{10}$ based on the $99 \%$ percentiles of $\mathrm{C} 15$ is shown. The resulting $p$-values of the Anderson-Darling goodness-of-fit test are shown in (f) [Colour figure can be viewed at wileyonlinelibrary.com] 